University of St. Thomas, Minnesota

UST Research Online

2014

\title{
The Impact of Electronic Communication and Social Media on Child Welfare Practice
}

Sarah K. Breyette

University of St. Thomas, Minnesota

Follow this and additional works at: https://ir.stthomas.edu/ssw_mstrp

Part of the Clinical and Medical Social Work Commons, and the Social Work Commons

\section{Recommended Citation}

Breyette, Sarah K., "The Impact of Electronic Communication and Social Media on Child Welfare Practice" (2014). Social Work Master's Clinical Research Papers. 292.

https://ir.stthomas.edu/ssw_mstrp/292

This Clinical research paper is brought to you for free and open access by the School of Social Work at UST Research Online. It has been accepted for inclusion in Social Work Master's Clinical Research Papers by an authorized administrator of UST Research Online. For more information, please contact asle4660@stthomas.edu. 
Running Head: ELECTRONIC COMMUNICATION AND SOCIAL MEDIA

The Impact of Electronic Communication and Social Media on Child Welfare Practice

by

Sarah K. Breyette, B.S.

MSW Clinical Research Paper

Presented to the Faculty of the

School of Social Work

St. Catherine University and the University of St. Thomas

St. Paul, Minnesota

In partial fulfillments of the Requirements for the Degree of

Master of Social Work

Committee Members

Dr. Katharine Hill, Ph.D., MSW, MPP, LISW (Chair)

Tracy Crudo, MSW

Faith Jaspersen, LICSW, MSW

Mary Lennick, MSW

The Clinical Research Project is a graduation requirement for MSW students at St. Catherine University/University of St. Thomas School of Social Work in St. Paul, Minnesota and is conducted within a nine-month time frame to demonstrate facility with basic social research methods. Students must independently conceptualize a research problem, formulate a research design that is approved by a research committee and the university Institutional Review Board, implement the project, and publicly present the findings of the study. This project is neither a Master's thesis nor a dissertation. 


\title{
Acknowledgements
}

First and foremost, I would like to say thank you to my committee members: Katharine Hill, Tracy Crudo, Faith Jaspersen, and Mary Lennick.

Thank you to my chair, Dr. Katharine Hill. Your knowledge, guidance and support throughout this process have been invaluable. Thank you for always challenging me to produce the best result.

Thank you to Tracy Crudo for your commitment to this project and to the field of social work. Without your support in the creation and implementation of this research, this study would not have been possible.

Thank you to Faith Jaspersen and Mary Lennick for continuing to shape my passion for social work and child welfare practice. Both of you embody the spirit of social work in a way that has deeply inspired me and I feel privileged to have had the opportunity to learn from you.

As Faith stated at the beginning of this process, "It takes a village to finish these research projects." I want to say thank you to my entire committee for being my village. Thank you for taking time out of your busy schedules to provide me with the expertise, knowledge, and guidance needed to complete this research.

I would also like to thank Dr. Carol Kuechler for sparking this research interest within me during my first semester at St. Catherine University/University of St. Thomas School of Social Work. Thank you for your continued support in this research and in my professional development as a social worker.

Finally, I would also like to say thank you to my friends and family for continually encouraging and supporting me throughout my graduate school journey. Your understanding and support over these past two years have been crucial in allowing me follow my passion. Thank you.

\begin{abstract}
The present literature regarding the intersection of technology and child welfare practice
\end{abstract}


has primarily focused on the impact of these technologies on youth and families. There has been very little research that has focused on how child welfare workers perceive the direct impact that electronic communication and social media use has had on their practice. The research questions guiding this exploratory study asked child welfare workers whether or not the use of electronic communication and social media has made working with youth easier, if use of these technologies has introduced any difficulties, and if any challenges and/or benefits of using these technologies have emerged that have not previously been discovered in the literature. One hundred and thirty-six child welfare workers completed an anonymous online survey addressing their experiences regarding the impact that electronic communication and social media use has had on their practice. The findings indicate that e-mail and text message use have made work with youth easier, yet distinct difficulties have emerged for practitioners in relation to electronic communication and social media use. Within the qualitative findings, new elements have emerged including issues with harassment and the ethics related to monitoring clients' online activities. Future research is necessary in order to address the limitations of this study and to stay current with the impact that emerging technologies might have on social work practice. 


\section{Table of Contents}

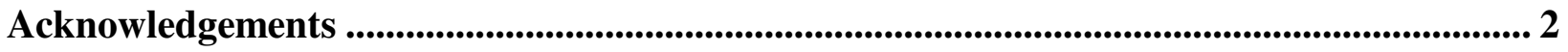

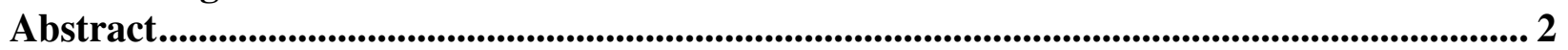

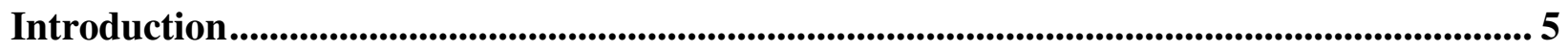

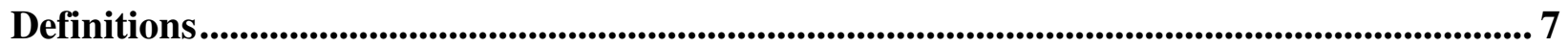

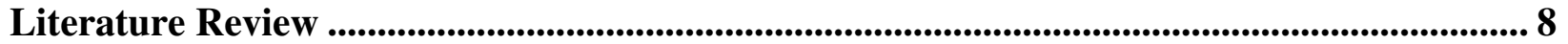

The Current Impact on Social Work Practice .............................................................................................8

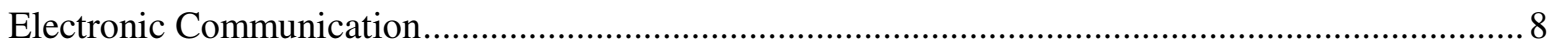

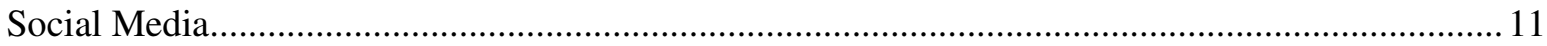

The Current Impact on Child Welfare Practice ..............................................................................13

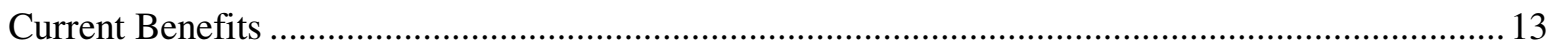

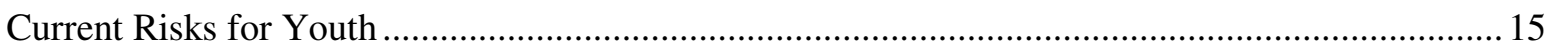

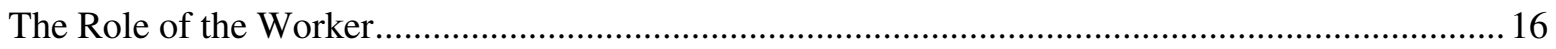

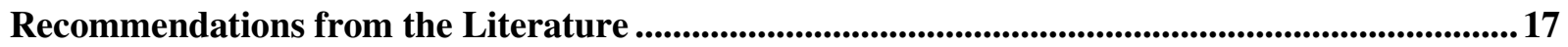

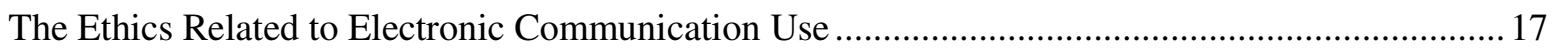

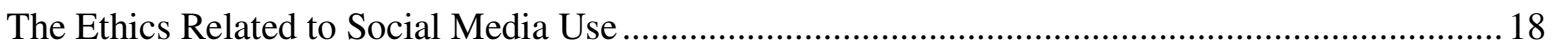

The Present Study: Purpose Statement and Research Questions .......................................... 19

Theoretical Framework: Ecological Systems Theory .................................................................... 20

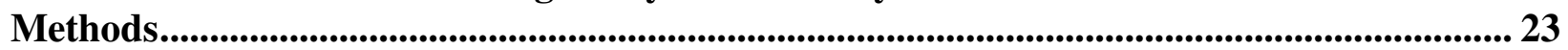

Research Design ..........................................................................................................................................................24

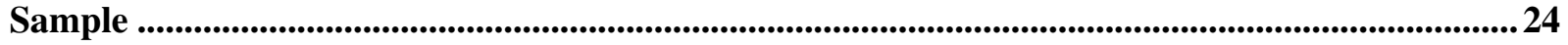

Protection of Human Subjects.......................................................................................................................25

Data Collection: Instrument and Process.......................................................................................................... 25

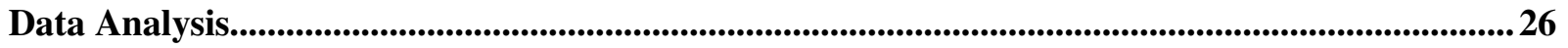

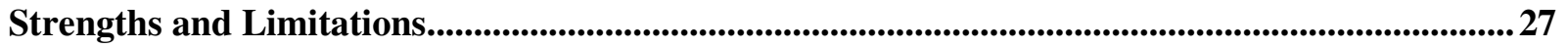

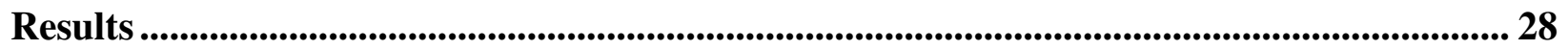

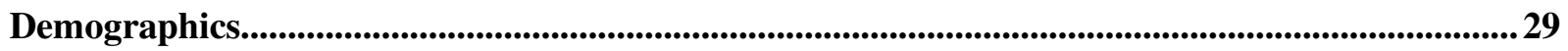

Quantitative Findings: Electronic Communication.....................................................................................30

Qualitative Findings: Electronic Communication ......................................................................................38

Quantitative Findings: Social Media .....................................................................................................48

Qualitative Findings: Social Media.....................................................................................................................55

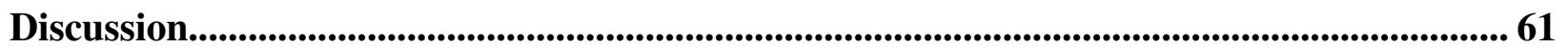

Purpose Statement and Research Questions ...............................................................................................661

Connections to the Current Literature...............................................................................................64

The Changes in Trends from 2006-2014 ..................................................................................................70

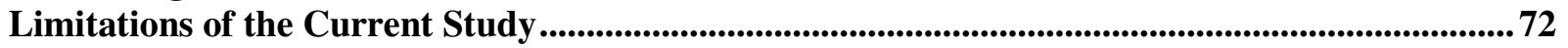

Implications for Social Work Practice...................................................................................................................73 73

Implications for Future Research .................................................................................................................... 73

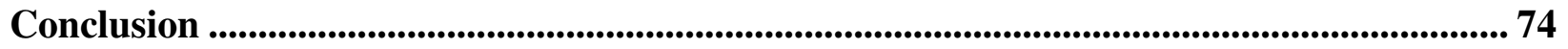

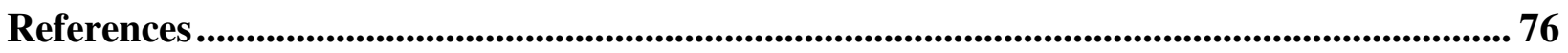

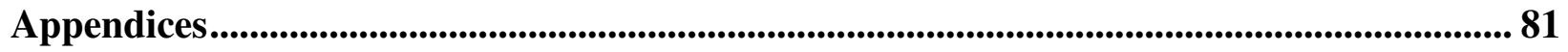

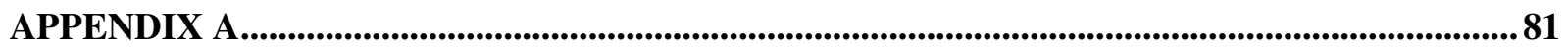

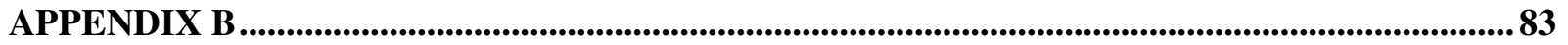




\section{The Impact of Electronic Communication and Social Media on Child Welfare Practice}

Over the past decade, the use of electronic communication and social media has steadily increased for youth (Ahmendani, Harold, Fitton, \& Shifflet Gibson, 2011). During that time, it has been made clear that youth's use of these technologies affects the work that is done by social workers. Although the effects of technological developments have impacted all social workers, this impact is especially relevant to child welfare workers' that work primarily with youth and families. Due to the fact that young people are typically the earliest adopters of most of these technologies, youth have become prime targets for these developments. In fact, youth today are more connected than they have ever been in the past (Ahmendani et al., 2011). In terms of media use and media exposure, the percentages for youth have only increased in the past fifteen years. For example, in 1999, the average total media exposure (i.e. media activities that are done while multitasking) for youth between the ages of eight and eighteen was seven hours and twenty-nine minutes per day. In 2010, this number increased to ten hours and forty-five minutes (Rideout, Foehr, \& Roberts, 2010).

With the increase of media use and exposure, the rates of internet and cell phone use have also risen dramatically for youth between 2005 and 2013 (Madden, Lenhart, Duggan, Cortesi, Gasser, 2013; Rideout, Foehr, \& Roberts, 2010). For example, in 2013, 78\% of youth owned their own cell phone as compared to only 40\% in 2005 (Madden et al., 2013; Rideout et al., 2010). Not only do more young people have their own cell phones, $47 \%$ of these teens own a smartphone (i.e. a phone with internet capability). In 2010, it was reported that, of teen cell phone owners, $88 \%$ frequently use text messaging and $54 \%$ use text messaging every day (Lenhart, Ling, Campbell, Prucell, 2010). Moreover, two-thirds of these youth have reported 
being more likely to text their friends and family than to call them (Lenhart et al., 2010). It is likely that these numbers have only increased in the past few years.

In terms of internet use, many youth today are spending more time using their phones, tablets and computers for social networking and web surfing as compared to the past (Madden et al., 2013; Rideout et al., 2010). Between 2005 and 2010, there was an increase among young people of almost a half hour each day of computer use that was unrelated to schoolwork (Rideout et al., 2010). This increase of computer use included time spent with online activities such as social networking, instant messenger services, e-mail, chat rooms and video games (Ahmendani et al., 2011). It is important to mention that, although not all youth have home internet access, 93\% currently do (Madden et al., 2013).

It is interesting to note that the preferred technologies have been changing rapidly. In 2011, many youth reported that their favorite, most-used form of technology was the computer (Ahmendani et al., 2011). The emergence of smartphones coupled with the fact that one in four teens are now "cell-mostly" internet users means that it is possible that this has changed over the course of two years (Madden et al., 2013, p. 2). It also means that even youth without home internet access are now able to access social networking and other internet-based sites through their cell phone service.

Many of the previous statistics reflect the average teen's experience with technology. It is important to mention that many of the youth that child welfare practitioner's have worked with have been historically more disadvantaged in terms of technology use than their more affluent counterparts. This concept, which states that individuals with fewer resources typically have less access to technology, is referred to as the digital divide. Although there is no current research regarding youth and the digital divide, it is possible that this divide has decreased in the past 
decade with growing access to different technologies. Regardless, this element is important to keep in mind while exploring the intersection of technology and social work practice.

The current research, which will be explained more in-depth in the following review of the literature, has made it clear that the emergence of technology has had an impact on young people and how they relate to others. It is less clear how this impact is perceived, especially by child welfare workers that work primarily with youth and families. Within the small sphere of research on electronic communication and social media, there is an even smaller amount of research on how exactly child welfare workers feel about the impact that these technologies has had on their practice. The current study aims to examine child welfare workers' attitudes regarding the impact of electronic communication and social media use with clients.

\section{Definitions}

This study examines the impact of electronic communication and social media. There are varying ideas about what electronic communication and social media actually include. For the purpose of this study, electronic communication includes both text messaging and e-mail use. Social media is also examined in the current study. Social media sites are websites where the primary function is social networking that allows users to connect with their friends and family online. Many social media websites allow users to share updates and photographs as well as content found online. Google+, LinkedIn, Facebook, Twitter and Instagram are all examples of social media websites. Direct social media use with clients typically includes activities such as accepting friend and follower requesters, personal messaging with clients, liking each other's posts, etc. Indirect social media use with clients includes activities such as using social media for relationship-building or social mapping with friends and family. 


\section{The Current Impact on Social Work Practice}

\section{Electronic Communication}

Benefits. There are quite a few benefits to e-mail communication with clients. For many social workers, the adage "start where the client is at" has been the primary reason for using these technologies with their clients (Mishna, Bogo, Root, Sawyer \& Khoury-Kassabri, 2012, pp. 280). Social workers have reported that they tend to get more responsive interactions when they have used e-mail communications with clients as compared to traditional, face-to-face methods of communication (Finn, 2006). One reason for this is that the convenience of e-mail communication allows for both the social worker and client(s) to communicate more comfortably (Bradley \& Hendricks, 2009). For family work, this can be an especially helpful addition to faceto-face contact because all members are able to communicate at a time and place that is convenient for each member (Bradley \& Hendricks, 2009). It may also be easier for clients to communicate via e-mail because there is less rush than with other forms of communication (Bradley \& Hendricks, 2009; Mishna, et al., 2012). Not only does e-mail allow for more comfort and less rush for both clients and social workers, it has also been shown to be especially helpful in scheduling appointments with clients (Mishna et al., 2012). In terms of barriers, e-mail use may make it easier to connect services to clients who might not otherwise be able to access services (e.g. individuals with hearing challenges and geographically-isolated clients) (Mishna et al., 2012; Reamer, 2013). For individuals who cannot access services during normal business hours, this form of communication may remove that barrier as well (Reamer, 2013). It also tends to be less expensive than face-to-face services, which is an added benefit for individuals from lower socio-economic backgrounds (Reamer, 2013). Aside from the listed benefits, e-mail communications can be documented more easily by saving a copy or just printing the e-mail and 
putting a copy of it in the client's file (Bradley \& Hendricks, 2009). Although there is not a lot of research on the benefits of text messaging with clients, many of the listed benefits of e-mail communication can be applied to text messaging communication as well.

Challenges. Before discussing the challenges, it is important to note that e-mail has been the most widely studied form of electronic communication in the past decade. Although much of the research on social workers' attitudes regarding the impact of technology has focused on email communications, many of the issues that occur with e-mail use also have the potential to occur with text messaging.

Although there are many benefits to electronic communication, there are also quite a few challenges that occur as a result of using this form of communication. Many social workers report that a majority of the time, clients will initiate e-mail contact with them first (Mishna et al., 2012). Because technology is evolving so rapidly, there are not many agencies that have clear policies and procedures regarding e-mail communication. For social workers, this has led to a feeling of ambiguity and uncertainty regarding the ethics surrounding electronic communication with clients (Finn, 2006).

Mishna et al. (2012) has described four areas that are seen as a concern for practitioners who decide to use e-mail with their clients. These areas include the slippery slope, Pandora's Box, an ethical grey zone and the creation of permeable boundaries. The slippery slope is something that social workers do not typically see happening. One social worker described this phenomenon by stating: "It might start with an e-mail to change an appointment and then it can shift from that to e-mails about issues to a crisis with the client e-mailing a practitioner saying they're suicidal” (Mishna et al., 2012, p. 281). Using electronic communication with clients for administrative purposes could possibly transform into using these forms of communication for 
therapeutic reasons such as crisis communications (Reamer, 2011). The second concern, Pandora's Box, is the idea that once e-mail communication begins, it may be difficult to undo or limit this communication (Mishna et al., 2012, p. 281). While using electronic communication with clients, practitioners may feel the need to be available 24/7 to avoid issues that may arise if the worker does not respond in a timely manner (Kassaw, 2002). The third concern, the ethical grey zone, occurs because there is a possibility for ethical issues when social workers engage in electronic communication (Kassaw, 2002; Mishna et al., 2012, p. 282; Reamer, 2012; Reamer, 2013). For example, an e-mail that contains client information may possibly violate client confidentiality if it is sent to the wrong person (Finn, 2006). The final issue, permeable boundaries, may occur for a variety of reasons such as overly friendly tones or difficulty pulling back communication (Mishna et al., 2012, p. 283). The use of e-mail and text messaging communications allow for more open boundaries that social workers typically try to avoid. The lack of non-verbal cues that typically occur during face-to-face communication has the potential to confuse the client and create even more inappropriate boundaries if they are not addressed by the social worker (Kassaw, 2002; Reamer, 2011).

Although many of the challenges of e-mail use can be applied to text messaging, there are likely unique issues that exist for text message use with clients. For example, with text messaging, cell phones are the only form of technology that can be used with this communication platform. In that sense, this form of technology can be very limiting for workers. It is important to note that text messaging is one of the most limiting communication platforms overall. This is mainly because the language used in text messages is usually shorter and has a greater potential to be misconstrued. In terms of agency policy, some agencies may require workers to use a work phone whereas others may allow workers to use their personal cell 
phones. Both of these options have the potential to present challenges. If a practitioner uses his or her personal cell phone, boundary issues around appropriate communication topics and response times may present themselves. The implied intimacy that can occur with text message use as opposed to other forms of communication might only further exacerbate this problem. Although this may be less common when workers are supplied with a work cell phone, it still has the potential to occur.

\section{Social Media}

Benefits. There is not much research that examines the potential benefits of social media use in regard to social work practice. However, many of the benefits of e-mail and text messaging may also be applicable to social media. For example, as previously discussed, the idea of "starting where the client is" could be applied to social media use. Similarly, social media may create more responsive reactions and less rush while at the same time increasing the ease of documentation. Although most of the literature does not address the benefits of social media use in social work practice, some practitioners believe that there is a danger in creating barriers between clients and workers if this technology platform is avoided. For example, for community organizers, it may be more difficult to connect with the community if workers are putting barriers in place when it comes to social media use (Robb, 2011). It is also possible that social media may beneficial for workers when helping clients map informal social supports. As social media use continues to grow, it is likely that more benefits will begin to emerge for this form of technology. It is also possible that future research will show benefits to social media that are similar to those experienced with electronic communication such as more responsive interactions from clients and a greater ease of documentation. 
Challenges. Robb (2011) has stated "when social workers misuse these [social media] tools, they can irreparably harm clients, sabotage their own careers and cast a long shadow over [the] profession" (p. 8). Although social media has created a greater sense of community between individuals and their social networks, it has also allowed, purposefully and inadvertently, a larger amount of personal information to be revealed to a larger number of people including friends, colleagues, and professional peers (Judd \& Johnston, 2012). For some, personal social media use is even seen as another form of self-disclosure that practitioners need to be mindful of (Reamer, 2009). When practitioners are not mindful of their privacy settings on social networking sites, they run the risk of revealing personal information that could be detrimental to the relationship between themselves and their clients (Gabbard, Kassaw, \& PerezGarcia, 2011; Reamer, 2012). Professionals also have the added pressure of having to exert caution to avoid using bias and derogatory language that could negatively impact clients if it is seen (Judd \& Johnston, 2012). Professionals found to be posting content that uses bias, derogatory language or shows the practitioner engaging in inappropriate behaviors and activities may also be violating professional social work standards (Reamer, 2012; Reamer, 2013). Even with privacy settings enacted, an individual's profile picture can still be seen, which can inadvertently reveal personal information about the practitioner (Gabbard et al., 2011).

For social workers with an online social media presence, this means that the line between their personal and professional lives becomes blurred and that there is a greater potential for boundary issues to arise (Judd \& Johnston, 2012). For example, if a professional sends or accepts a "friend request" on a social networking site, both the client and the practitioner now have access to a multitude of personal information. Clients might also interpret this as an actual friendship and the potential for dual relationship issues only becomes more concerning (Gabbard 
et al., 2011; Reamer, 2011). Alternatively, if a practitioner does not accept a friend request form their client, the client may experience issues with rejection, which is another challenge that practitioners need to address (Reamer, 2012).

Another issue that emerges is that practitioners are violating privacy and confidentiality standards if found to be posting information about clients (Gabbard et al., 2011). This "breach in confidentiality" has a great potential for harm in terms of its effect on clients and their families (Gabbard et al., 2011, p. 171). Having an online social media presence may create an added element of risk for the client and practitioner relationship because the client may feel less trusting that the social worker will hold to confidentiality and privacy guidelines when posting online (Gabbard et al., 2011; Judd \& Johnston, 2012).

Many clients and families have used their online presence as a way to express themselves, either negatively or positively (Gabbard, 2012). Although this can be helpful for the client, it also has the potential to complicate the relationship between the client and the practitioner. For example, the client may express one thing to the practitioner and then express an entirely different viewpoint online (Gabbard, 2012). As a result, another issue that presents itself is whether or not it is ethical for the practitioner to search for this kind of information online and if conducting that search would violate the boundaries of the relationship (Huremovic \& Rao, 2009).

\section{The Current Impact on Child Welfare Practice}

\section{Current Benefits}

As stated previously, many young people prefer to communicate through electronic technologies. As a result, numerous child welfare agencies have begun using these technologies as avenues to create more comfortable and open communication with clients (Reamer, 2013). 
There are quite a few benefits for youth that exist as a result of child welfare workers embracing the use of electronic communication and social media. As discussed previously, electronic communication has the potential to remove barriers for individuals who would otherwise remain isolated from services. For young people who are shy or under-confident, electronic communication and social media are less intrusive interventions that allow these youth to connect with adults and other peers (Ahmendani et al., 2011). Electronic communication and social media may also be helpful when working with youth who are experiencing issues that stem from geographic isolation, social embarrassment and emotional distance (Tregeagle, 2011). Again, the ease of communication allows for more responsive, convenient interactions that allow the young person to communicate when they are able.

Because youth are so connected to technology, these technologies have the potential to be used as a tool for engaging more youth and encouraging more self-disclosure that might be difficult to achieve in face-to-face communication (Tregeagle \& Darcy, 2007; Tregeagle, 2011; Whitaker, Torrico, Meruvia \& Jones, 2010). Additionally, young people are able to have greater control over what information is presented about them and who has access to this information (Tregeagle, 2011). For example, through the use of privacy settings on social media sites, youth are able to self-disclose information only to the individuals they choose to disclose to. For at-risk youth within the child welfare system who might otherwise feel as if others control their identity, they are able to disclose a narrative on their own story, which may allow them to regain power over their own story (Boyd, 2007).

Many social workers have reported that they see the potential for electronic communication and social networking to help engage clients and assist families in a greater capacity (Whittaker et al., 2010). It has been discovered that the emergence of smartphones has 
been helpful for many child welfare workers', particularly when attempting to communicate with foster and adoptive parents or when trying to monitor children who are currently in the foster care system (Schneider \& Evans, 2011). Not only do these technologies have the potential to create more responsive interactions from youth and families, they have also been reported to increase efficiency for many child welfare workers because the worker is able to communicate in a more convenient manner (Whitaker et al., 2010). For these reasons, it has been stated that not using this medium has the potential to actually damage the worker-client relationship because it can limit communication between the worker and the young person (Tregeagle \& Darcy, 2007; Tregeagle, 2011). It is important to note that previously discussed benefits of electronic communication and social media, such as ease of documentation and a greater sense of connection to the community, are also applicable to work with youth and families.

\section{Current Risks for Youth}

Although these fairly new forms of communication could prove beneficial, there are still potential risks to these new technologies such as increased vulnerability of young people and increased risk of youth experiencing negative interactions such as cyber bullying (Finn \& Kerman, 2003; Tregeagle \& Darcy, 2007). Regardless of this risk, young people have a need to keep in contact with others (Livingstone, 2011). This is especially true for youth who are in outof-home placements. With the ever-rising popularity of social media websites, it is now possible for young people to more easily stay connected to others (Livingstone, 2011). Some youth in out-of-home placements are using this form of technology to connect with their biological families and former peer groups (Bodner \& Knapp, 2011; Finn, 2011). The current research has shown that $44 \%$ of youth in foster care use Facebook and text messaging to connect with their family members each week (Bodner \& Knapp, 2011). Depending on the situation, this can either 
be a benefit or a challenge. More specifically, for a majority of youth in care, these connections have been positive but for youth whose biological families and former peer groups have historically had a negative impact on the young person, this can be damaging or dangerous (Bodner \& Knapp, 2011; Fursland, 2011). This is especially true if the child has previously experienced trauma or abuse (Fursland, 2011).

\section{The Role of the Worker}

For many young people, electronic communication and social media allow youth to take more risks and experiment with their "display of self" (i.e. their depiction of themselves through electronic communication and social media) (Livingstone, 2011). The emergence of electronic communication and social media provide an opportunity for child welfare workers to educate young people about privacy and safety when using these technologies. This education is something that many young people have reported would be helpful, especially when attempting to reconnect with their biological families (Bodner \& Knapp, 2011). Some child welfare agencies have begun incorporating an education component for youth in regard to electronic communication and social media (Finn, 2011). For these agencies, education around these issues is seen as a "life skill that is important for successful transition into adulthood" and has been reported to be helpful in protecting young people from any dangerous situations that might arise as a result of technology use (Finn, 2011, p. 17). More often, the young person's social worker is becoming the primary individual who provides interventions when at-risk youth experience situations related to technology use that leave them more vulnerable (Livingstone, 2011; Miller 2011). For some workers, this becomes a challenge if they feel they do not fully understanding these technologies (Ledesma \& Casavant, 2011; Tregeagle, 2011). Regardless, social workers 
are encouraged by the NASW and ASWB (2005) standards for technology and social work practice to stay current with emerging technologies (p. 10).

\section{Recommendations from the Literature}

In response to the challenges that have been presented as a result of electronic communication and social media, recommendations for the ethical use of technology have emerged in the current literature. It is important to note that social workers need to be aware that Sections 1.03 and 1.07 of the NASW Code of Ethics (2008) discuss guidelines for social workers in terms of electronic communication and social media use. These sections state that not only are social workers required to take precautions that guard against the previously discussed concerns, they also have a responsibility to offer services based on valid and informed consent that educates clients about the risks of these forms of communication (Kassaw, 2002; NASW, 2008; Reamer, 2011).

\section{The Ethics Related to Electronic Communication Use}

Although social workers should always warn clients about privacy and confidentiality issues, limits also need to be set with clients about what is appropriate to discuss via electronic communication. This will help avoid any potential boundary issues that may occur (Bradley \& Hendricks, 2009; Bradley, Hendricks, Lock, Whiting \& Parr, 2011). Clients should also be informed of how frequently e-mails will be checked and responded to in order to avoid any confusion that may affect the therapeutic relationship (Bradley et al., 2011; Kassaw, 2002). In terms of record-keeping, any e-mail communication that could be considered clinical or counseling-related, excluding administrative e-mails, should be printed off and become a part of the client's file as any other document would (Bradley \& Hendricks, 2009; Bradley et al., 2011; Kassaw, 2002; Reamer, 2011). Workers who use e-mail and text communications should use 
precautionary measures against breaches in confidentiality by using encryption and firewall software as well as "web-based messaging” (Finn, 2006; Kassaw, 2002). Along with using special software, practitioners should be using an e-mail signature that includes the following: "name and phone number...emergency contact, confidentiality, privacy, unauthorized access, intended user, times for checking e-mail, and any fees charged to read and respond to e-mail" (Bradley et al., 2011, p. 75). To help professionals follow proper guidelines and avoid the challenges of ambiguity and uncertainty regarding electronic communication, trainings should be provided for workers about policies and procedures that affect use of e-mail communication and text messaging in the workplace (Finn, 2006).

\section{The Ethics Related to Social Media Use}

The most prevalent recommendation in the literature in regard to social media use is that professionals should avoid dual relationships by not becoming Facebook friends with their clients (Judd \& Johnston, 2012; Gabbard, Kassaw, \& Perez-Garcia, 2011; Reamer, 2011). Much of the literature also recommends using all available privacy settings on social networks and to not assume that anything that is posted, even if protected under privacy settings, will remain private (Gabbard et al., 2011; Gabbard, 2012). For all methods of social media, practitioners should avoid posting any identifying client information or negative comments about clients in order to maintain confidentiality and professionalism standards (Gabbard et al., 2011).

Because social media is so new and there is not much research on how it has affected practitioners, it has been suggested that before offering recommendations for how to deal with ethical issues, there needs to be open dialogue between professionals regarding technology use and the implications for social work (Robb, 2011). As a result of these conversations, it will be important to incorporate guidelines into the NASW Code of Ethics, professional curriculums and 
agency social media policies (Gabbard et al., 2011; Reamer, 2011; Reamer, 2013; Robb, 2011). Until then, professionals should understand that, although they may not be violating any specific ethical codes, they should still be mindful that their online presence has the potential to violate professional standards (Gabbard et al., 2011).

\section{The Present Study: Purpose Statement and Research Questions}

It is clear that electronic communication and social media are impacting the work that child welfare workers do. The present literature regarding the intersection of technology and child welfare has primarily focused on the impact of these technologies on youth and families. Currently, there is very little research that is focused on how child welfare workers perceive the direct impact that electronic communication and social media use has had on their relationship with their clients. For example, the literature at the center of the intersection of technology and social work has examined some of the challenges that social workers generally experience (e.g. boundary issues, feelings of ambiguity and uncertainty, etc.) but this research has not been tailored to examine the specific challenges that child welfare workers experiences. In order to better serve clients and create a greater understanding of the current attitudes of child welfare workers in regard to technology use, the present study was designed. This study aimed to examine the experiences of child welfare workers in order to discover their attitudes regarding the impact of electronic communication and social media use with clients.

Much of the social work research regarding technology has examined electronic communication but only a small portion of the literature has examined social media. This study was exploratory by nature. The research questions guiding this study have emerged as the result of gaps in the previous literature. The first research question examines whether or not the use of electronic communication and social media have made work with youth easier for child welfare 
workers. The second research question explores if the use of electronic communication and social media has introduced any difficulties for child welfare workers. The third research question examines whether or not any challenges and/or benefits of electronic communication and social media use have emerged that have not previously been discovered in the literature.

\section{Theoretical Framework: Ecological Systems Theory}

Urie Bronfenbrenner's framework regarding Ecological Systems Theory was first introduced in the 1970's (Bronfenbrenner, 1994). This system continued to be revisited over the course of twenty years until the present day Ecological Systems Theory emerged. One of the main propositions of Bronfenbrenner's theory states that, throughout the course of an individual's life, he or she will experience many complex interactions with the environment. These interactions between the individual and the environments surrounding the individual are key components to development (Bronfenbrenner, 1994, p. 38).

Bronfenbrenner (1994) has explained that the environments that individuals experience can be broken down into five areas: the micro-system, the meso-system, the exo-system, the macro-system and the chrono-system. The first system, the micro system, is composed of the immediate environment surrounding a developing individual. The second system, the mesosystem, is the link between different systems. More specifically, the meso-system is the point where the micro-systems that impact the individual connect. The third system, the exo-system, is composed of multiple systems in which at least one of those systems does not directly involve the individual and his or her immediate microsystem. Although changes in the system do not directly involve the individual, they indirectly impact this individual. The fourth system, the macro system, is composed of the relations and patterns that exist between the micro-, meso-, and exo-systems. The macro-system can be seen as the larger societal aspects of the 
environment. The fifth and final system, the chrono-system, includes any historical changes that impact the individual or other systems (pp. 39-41).

An important piece of the Ecological Systems Theory is that all of these systems are interconnected and affect each other. Although the field of social work has primarily focused on the micro-, meso-, and macro-systems, the remaining two systems (i.e. the exo-system and chrono-system) are also an important part of Bronfenbrenner's perspective. It must be noted that, in regard to Bronfenbrenner's framework, when all systems are compatible, the experiences of the individual typically flow fairly smooth (Weber State University, n.d.).

This study examined child welfare workers' attitudes regarding the impact of direct use of electronic communication with clients and the impact of both direct and indirect use of social media with clients. When viewing these research areas through the lens of Ecological Systems Theory, it is clear that child welfare workers are currently experiencing difficulties learning how to cope with the changes that have occurred in the different systems as a result of the emergence of electronic communication and social media. This research is important in practice because the issues that have presented themselves as a result of the emergence of these technologies have the potential to be resolved with further understanding of how and why the environmental systems are currently incompatible.

In regard to the chrono-system, historical changes related to the intersection of child welfare and technology began in the 1980's with the introduction of the first electronic technologies (i.e. the State Automated Child Welfare Information Systems and the National Child Abuse and Neglect Data System). Although these technologies were created to improve worker efficiency, they ultimately added more stress to workers than had been anticipated (LaMendola, Glastonbury \& Toole, 1989). This appears to have been the starting point for the 
incongruence of technology use within the macro and micro systems of child welfare. From a macro standpoint, the new technologies were proving beneficial in regard to efficiency of the agencies. On the other hand, from a micro standpoint, these technologies had a more negative impact on workers than what was expected. Since this point, as more technologies have been introduced, the pattern of incongruence between micro, mezzo and macro systems has only continued and child welfare workers have had to attempt to manage changes within each system that are continuously interacting with each other.

In terms of the present study, the issues that are currently occurring exist within the micro-, meso- and macro-systems. In the micro-system, an example of this can be see by the challenges that are faced when workers attempt to limit electronic communication after this avenue has already been used with a client. In regard to the meso-system, an example of this can be seen by the challenge of permeable boundaries that workers now face between their personal and professional lives. Finally, in regard to the macro-system, presenting issues are evidenced by the response of professional associations such as NASW to incorporate ethical standards for technology-related practice. These are just a few examples of how the issues that exist as a result of the emergence of electronic communication and social media relate to the micro-, meso- and macro-systems.

Currently, child welfare workers are working within the center of these systems, attempting to manage the changes that are quickly and continuously occurring. As an integral part of these systems, it is important to explore the perspectives of these workers. The current study attempts to examine these experiences in a way that will help create more compatibility between these systems in the future. 


\section{Methods}

The purpose of this study was to explore child welfare workers' attitudes regarding the impact of electronic communication and social media use with clients. This study used an electronic mixed-method survey, hosted on the website Qualtrics, to examine respondents' attitudes regarding this topic. The sample for this study included individuals who work within the child welfare system. These respondents were found through a non-probability snowball sample. After the data was collected, it was analyzed in order to examine the following research questions:

1. Has the use of electronic communication and social media made communications made work with youth easier for child welfare workers?

2. Has the use of electronic communication and social media introduced any difficulties for child welfare workers?

3. Have any challenges and/or benefits of electronic communication and social media use emerged that have not previously been discovered in the literature?

\section{Research Design}

The research design for this study was mixed-methods, utilizing both qualitative and quantitative methods. A written survey containing closed and open-ended questions was used to examine the research questions. The survey was divided into five sections to examine the following: demographics, e-mail use, text message use, social media use and the qualitative answers of the respondents. The first four sections of the survey examined specific aspects of electronic communication and social media that have been defined by the literature. These sections were primarily quantitative. The final section was qualitative. This section of the survey examined ethical dilemmas that child welfare workers have experienced as well as any other 
impact they have seen as a result of electronic communication and social media. Electronic communication and social media were examined more broadly in this section based on the lack of previous literature regarding the intersection of technology and social work. These qualitative questions aimed to meet the need for more exploratory research on the topic (Monette, Sullivan \& DeJong, 2011). Qualtrics, an online survey tool, was used to distribute the survey and collect answers.

\section{Sample}

Through a non-probability snowball sample (Monette et al., 2011), the survey was given to individuals who work within the child welfare system such as public, private and tribal social workers and child protective services (CPS) workers. Respondents received an e-mail containing a link to the survey on Qualtrics. Participants were asked to complete the online survey and forward the e-mail to other child welfare workers. The survey was expected to take approximately twenty minutes to complete. The principle investigator for this study had professional contacts within the child welfare system in the Twin Cities region to whom she sent the initial e-mail.

This type of sample was chosen because it allowed respondents to identify other potential respondents that might have insight on the topic (Dawson, Klass, Guy \& Edgley, 1991). Due to the time constraints of the study, this method had the potential to allow for the largest number of respondents. This type of sample also allowed for accessibility and ease of use for respondents who have busy schedules. Because the survey was hosted online, the respondents were not restricted to any geographical areas. The study was aiming for at least 50 respondents. 


\section{Protection of Human Subjects}

This study was reviewed and approved by both a research committee and the Institutional Review Board (IRB) at the University of St. Thomas in St. Paul, Minnesota to ensure that human subjects would be protected. The intended respondent sample coupled with the research topic did not infer any issues regarding vulnerability. There were no known risks for harm or discomfort for respondents in this study. The questions that were asked of respondents were not known to cause any potential harm, as they were related to the professional responsibilities of the worker. Although respondents did add to the current knowledge base surrounding the intersection of child welfare and technology, there were no direct benefits to participation in this study. The initial e-mail that was sent to respondents included a link to complete the survey on Qualtrics and a request to forward the e-mail to other child welfare workers. Informed consent was obtained at the start of the survey. This allowed the respondents to know and understand the voluntary nature of the study. Respondents were directed to review the consent form (Appendix A) at the start of the survey. Completion of the survey implied respondent consent. The electronic survey was anonymous so no identifying information was collected on Qualtrics. Due to this fact, no identifiable information was used in the data analysis or final report of the findings.

The data that was collected through Qualtrics was kept on the principle investigator's password-protected personal computer. All data will be destroyed upon completion of the study, no later than June 1, 2014. The Qualtrics account that is associated with this study will also be deactivated at the conclusion of the study, no later than June 1, 2014.

\section{Data Collection: Instrument and Process}

The instrument used for this study was a mixed-methods questionnaire that was created by the principle investigator (Appendix B). The survey was divided into five sections. The first 
section of the survey included demographic questions. The next three sections of the survey examined e-mail use, text message use and social media use. The questions for this portion of the survey were adapted from previous research done by Jerry Finn in 2006 regarding social workers' attitudes surrounding e-mail communications. These questions have been adapted in order to address electronic communication and social media in the context of the current study. Drawing from the previous literature helped to ensure the quality of the questions that were asked.

Open-ended questions were created and included in the final portion of the survey in order to explore worker experiences. More specifically, this portion examined worker experiences in regard to ethical dilemmas that have been experienced as well as any other impact they have seen as a result of electronic communication and social media. These open-ended qualitative questions allowed electronic communication and social media to be examined more broadly. These measures contained face validity after being reviewed by the research chair and committee members for this study (Monette et al., 2011).

Qualtrics, an online survey tool, was used to distribute the survey and collect the data. The initial e-mail that was sent to respondents contained a link to the Qualtrics survey. In this email, respondents were also be asked to forward the e-mail to other child welfare workers in order to further the scope of the snowball sample.

\section{Data Analysis}

All data was analyzed using Qualtrics and SPSS software. Descriptive statistics such as frequency, measures of central tendency and dispersion, bar charts and histograms were found for all corresponding variables. The first research question examined whether or not the use of electronic communication and social media have made working with youth easier for child 
welfare workers. In order to examine this question, respondent answers to the following survey questions were examined: \#6, \#26, and \#46. These survey questions asked respondents to report which statement most accurately describes their experience with e-mail/text message/social media use. Respondent options were: e-mail/text message/social media use has made my work with clients easier, there has been no change in my work as a result of e-mail/text message/social media use, and e-mail/text message/social media use has made my work with clients harder. The second research question explored if the use of electronic communication and social media has introduced any difficulties for child welfare workers. This question was examined by exploring respondents' answers to the questions related to difficulties experienced while using e-mail, text messaging, and social media in work-related situations. The third research question examined whether or not any challenges or benefits of electronic communication and social media have emerged that have not previously been discovered in the literature. Common themes were pulled from the qualitative responses and were analyzed using thematic analysis. The themes were examined as they related specifically to the third research question, but were also examined in relation to the initial two research questions. The quotations included in the qualitative analysis were edited for spelling and basic grammar mistakes before analysis. No editing was done that changed the meaning of the responses.

\section{Strengths and Limitations}

There are a few strengths of this study that should be addressed. Using Qualtrics to host the survey allowed for ease and accessibility of use in order to find a greater number of respondents. Because child welfare workers have busy schedules, this electronic survey was helpful in that respect. Also, previous literature has been used to guide the creation of the survey that was used in this study. This means that portions of the survey have been used empirically in 
the past. Additionally, the new sections of the survey aimed to explore gaps in the current literature. This allowed for expansion of the social work knowledge base regarding the intersection of child welfare and technology.

There were also some limitations that existed as well. First, using a non-probability snowball sample made the study less generalizable (Monette et al., 2011). Additionally, the online platform of Qualtrics, although helpful in terms of accessibility, may have created a sample that consists of individuals who are biased toward electronic communications and technologies. It is also important to note that the survey that was created was not standardized and could potentially have issues with reliability and validity.

\section{Results}

The purpose of this study was to examine the experiences of child welfare workers regarding the impact of direct use of electronic communication with clients and the impact of both direct and indirect use of social media with clients. This study was primarily exploratory. As stated previously, the research questions guiding this study emerged as a result of gaps in previous literature. The first research question explored the possibility that the use of electronic communication and social media have made working with youth easier for child welfare workers. The second research question asked whether or not the use of electronic communication and social media have introduced any difficulties for child welfare workers. Finally, the third research question explored the potential emergence of any challenges and/or benefits of electronic communication and social media use that have not been previously discovered.

In total, there were 158 surveys that were started. Twenty-two respondents did not complete the survey. These responses were not included in the analysis, which means that the total number of respondents was 136. The findings show that, although e-mail and text message 
use appear to make communication with youth easier for child welfare workers, the use of social media has not had a clear impact on work with youth. In terms of difficulties that may have been introduced as a result of electronic communication and social media use, these difficulties have occurred mostly for e-mail use, as opposed to text message and social media use. In relation to the final research question, the findings of this study support the previous literature. No themes emerged within the qualitative data that have not been discussed in some capacity in the previous literature, but new elements emerged including issues with harassment and the ethics related to monitoring clients' online activities.

\section{Demographics}

Age. The first demographic variable that was measured was respondent age. Measures of central tendency were computed to summarize the data for this variable. Measures of dispersion were also computed to understand the variability of scores for this variable. Of the 107 respondents that answered this survey question, the average age was 43.93 years $(S D=11.42)$. The minimum age was 22 years and the maximum age was 71 years.

Agency Type. The second demographic variable that was measured was agency type. This variable explored what kinds of agencies were represented within the sample. Respondents were asked at which kind of agencies they work. The response options were: public, private, tribal, school, clinical, and other (136). These findings, as seen in Table 1, show that 115 respondents $(84.6 \%)$ reported working at a public agency, 15 respondents $(11.0 \%)$ reported working at a private agency, 1 respondent $(.7 \%)$ reported working at a tribal agency, 1 respondent $(.7 \%)$ reported working at a school-based agency, 2 respondents $(1.5 \%)$ reported working at a clinical agency, and 2 respondents (1.5\%) chose "other." These respondents described the agencies where they work as: "non-profit (public)" and "hospital." These findings 
show that a majority of respondents work at public agencies.

Agency Characteristics. Next, the characteristics of these agencies were measured.

Respondents were asked about the characteristics of the place where they work. The response options were: rural, suburban, urban, and mixed (136). The findings of this study show that 59 respondents $(43.4 \%)$ described the characteristics of the place where they work as rural, 22 respondents (16.2\%) described the characteristics as suburban, 18 respondents (13.2\%) described the characteristics as urban, and 37 respondents $(27.2 \%)$ described the characteristics as mixed. These findings, as seen in Table 1, show that a majority of respondents work in rural areas.

Professional Experience. The final demographic variable that was measured was the level of professional experience of the respondents. This variable explored how long respondents have worked within their field. The response options for this survey question were: 0-5 years, 610 years, 11-15 years, 16-20 years, and 20+ years (135). As seen in Table 1, the findings of this study show that 27 respondents (19.9\%) reported 0-5 years of experience, 20 respondents (14.7\%) reported 6-10 years of experience, 32 respondents $(23.5 \%)$ reported $11-15$ years of experience, 22 respondents (16.2\%) reported 16-20 years of experience, and 34 respondents $(25 \%)$ reported $20+$ years of experience. One respondent $(.7 \%)$ did not respond. These findings show a fairly even distribution of professional experience.

\section{Quantitative Findings: Electronic Communication}

Type of Cell Phone Used for Work Purposes. The type of cell phone that is used for work purposes was measured in this study. The response options were: work cell phone, personal cell phone, and no cell phone (136). The findings for this survey question can be seen in Table 1. These findings show that 44 respondents $(32.4 \%)$ reported that they use a work cell phone, 71 respondents $(52.2 \%)$ reported that they use a personal cell phone, and 21 respondents $(15.4 \%)$ 
reported that they do not use a cell phone for work purposes. (If respondents selected "no cell phone," the survey re-directed them to the next section of the survey, social media use.)

Table 1. Demographic data.

\begin{tabular}{lc} 
Characteristic & $\begin{array}{c}\text { Respondents }(\%) \\
(\mathrm{N}=136)\end{array}$ \\
\hline Agency Type & 84.6 \\
Public & 11.0 \\
Private & 0.7 \\
Tribal & 0.7 \\
School & 1.5 \\
Clinical & 1.5 \\
Other & \\
Agency Characteristics & 43.4 \\
Rural & 16.2 \\
Suburban & 13.2 \\
Urban & 27.2 \\
Mixed & \\
Professional Experience & 19.9 \\
0-5 years & 14.7 \\
6-10 years & 23.5 \\
11-15 years & 16.2 \\
16-20 years & 25.0 \\
20+ years & \\
Work cell phone & 32.4 \\
Personal cell phone & 52.2 \\
Do not use a cell phone at all & 15.4 \\
\hline
\end{tabular}

Frequency of Electronic Communication Use. The frequency of e-mail and text message use with clients was examined in this survey. Respondents were asked how frequently they use e-mail or text messaging with clients. The response options for each question were: never, rarely, sometimes, often, and daily. The total number of respondents for the variable in relation to e-mail use was 132 , compared to 113 respondents for text message use. The findings, as seen in Table 2, show that only 9 respondents $(6.6 \%)$ reported that they never use e-mail with clients, compared with 25 respondents $(18.4 \%)$ who reported that they never use text messaging 
with clients. Thirty-six respondents $(26.5 \%)$ reported that they rarely use e-mail with clients and 22 respondents $(16.2 \%)$ reported that they rarely use text messaging with clients. Forty-three respondents $(31.6 \%)$ reported that they sometimes use e-mail with clients, whereas only 26 respondents $(19.1 \%)$ reported that they sometimes use text messaging with clients. Twenty-seven respondents (19.9\%) reported that they often use e-mail with clients. Similarly, 24 respondents $(17.6 \%)$ reported that they often use text messaging with clients. Seventeen respondents $(12.5 \%)$ reported that they use e-mail with clients daily and 16 respondents $(11.8 \%)$ reported that they use text messaging with clients daily. Four respondents $(2.9 \%)$ did not respond to the e-mail use survey question. Twenty-one respondents $(15.4 \%)$ were re-directed to the next section of the survey due to the fact that they reported that they do not use a cell phone for work-purposes.

Table 2. Frequency of electronic communication use

\begin{tabular}{lccccc} 
& & & & & \\
Type of Technology & $\%$ Never & \% Rarely & \% Sometimes & \% Often & $\%$ Daily \\
\hline E-mail & 6.6 & 26.5 & 31.6 & 19.9 & 12.5 \\
Text Messaging & 18.4 & 16.2 & 19.1 & 17.6 & 11.8 \\
\hline
\end{tabular}

Impact of Electronic Communication. The survey also measured how respondents perceive the impact of e-mail and text message use on their work. Respondents were asked to mark which statement most accurately describes their experience with e-mail and text message use. The response options related to e-mail use were: e-mail use has made my work with clients easier, there has been no change in my work with clients as a result of e-mail use, and e-mail use has made my work with clients harder (134). In regard to text message use, the response options were: text message use has made my work with clients easier, there has been no change in my work with clients as a result of text message use, and text message use has made my work with clients harder (114). These findings regarding the impact of electronic communication can be found in Table 3. The findings show that 90 respondents $(66.2 \%)$ reported that e-mail use has 
made their work with clients easier. Similarly, 78 respondents $(57.4 \%)$ reported that text message use has made their work with clients easier. Forty-two respondents $(30.9 \%)$ reported that there has been no change in their work with clients as a result of e-mail use; and 31 respondents $(22.8 \%)$ reported that there has been no change in their work with clients as a result of text message use. Only 2 respondents $(1.5 \%)$ reported that e-mail use has made their work with clients harder; and only 3 respondents $(2.2 \%)$ reported that text message use has made their work with clients harder. Two respondents (1.5\%) did not respond to the survey question regarding the impact of e-mail use on their work. In regard to text message use, twenty-four respondents $(17.6 \%)$ either did not respond to the survey question or they were re-directed to the next section of the survey. These findings show that a majority of respondents reported that the use of electronic communication has made their work easier.

\section{Table 3. Respondent perceptions regarding the impact of electronic communication use}

Impact

Use has made my work with clients easier

There has been no change in my work with clients as a result of use

Use has made my work with clients harder

\section{Email (\%)}

66.2

30.9
Text Message (\%)

57.4

22.8
1.5

Beliefs about electronic communication use: $\boldsymbol{e}$-mail. Respondents were also asked to rate their agreement with the following statements: e-mail with client information should not be used because it violates client confidentiality; e-mail is useful because it saves time over telephone or face-to-face meetings; many clients respond more openly to workers through email; workers should generally give clients their e-mail address; e-mail is generally a burden to workers because it adds to their workload; and e-mail is an effective means for workers to provide ongoing services to clients (136). The ratings were based on a five point Likert-scale from (1) Strongly Disagree to (5) Strongly Agree. As seen in Table 4, over half of the 
respondents $(63.3 \%)$ did not agree that e-mail with client information should not be used because it violates client confidentiality. Similarly, a majority of respondents $(75.0 \%)$ disagreed that email is generally a burden to workers because it adds to their workload. Nearly three-fourths of respondents $(72.1 \%)$ agreed that e-mail is useful because it saves time over face-to-face meetings. Many respondents (66.9\%) also agreed that workers should generally give clients their e-mail address. In regard to providing ongoing services to clients, many respondents (55.9\%) reported that they agree that e-mail is an effective means to do so. Slightly more than half of respondents $(52.2 \%)$ neither agreed nor disagreed that clients respond more openly to workers through e-mail.

Table 4. Respondent agreement with beliefs about e-mail use

Beliefs $\%$ Agree (4-5) \% Disagree (1-2)

E-mail with client information should not be used because it 18.4 63.3 violates client confidentiality

E-mail is useful because it saves time over telephone or 72.1 10.3 face-to-face meetings

Many clients respond more openly to workers through e36.0 11.7 mail

Workers should generally give clients their e-mail address E-mail is generally a burden to workers because it adds to their workload

E-mail is an effective means for workers to provide ongoing services to clients

66.9

5.9

9.6

55.9
75.0

19.1

Beliefs about electronic communication use: text messaging. In relation to text message

use, respondents were asked to rate their agreement with the following statements: text messaging with client information should not be used because it violates client confidentiality; text messaging is useful because it saves time over telephone or face-to-face meetings; many clients respond more openly to workers through text messages; workers should generally give clients their cell phone numbers; text messaging is generally a burden to workers because it adds 
to their workload; and text messaging is an effective means for workers to provide ongoing services to clients (114). The ratings were based on a five point Likert-scale from (1) Strongly Disagree to (5) Strongly Agree. These findings, as seen in Table 5, show that a little over onethird of respondents $(39.0 \%)$ disagreed that text messaging with client information should not be used because it violates client confidentiality, whereas nearly one-fourth of respondents agreed with this statement (27.2\%). Over half of respondents $(52.2 \%)$ agreed that text messaging is useful because it saves time over telephone or face-to-face meetings. Close to half of respondents (46.3\%) also reported that they agree that many clients respond more openly to workers through their text messages. Similarly, many respondents $(42.0 \%)$ reported that they believe text messaging is an effective means for workers to provide services to clients. One-fourth of respondents $(24.2 \%)$ reported that they agree that workers should generally give their cell phone numbers to clients, whereas a little over one-fourth of respondents $(29.5 \%)$ disagreed with this statement. Over half of respondents $(58.1 \%)$ disagreed that text messaging is generally a burden to workers. Only a small percentage of respondents $(9.5 \%)$ agreed that text messaging with clients is a burden.

Table 5. Respondent agreement with beliefs about text message use

\begin{tabular}{lcc} 
Beliefs & \% Agree (4-5) & \% Disagree (1-2) \\
\hline $\begin{array}{l}\text { Text messaging with client information should not be used } \\
\text { because it violates client confidentiality }\end{array}$ & 27.2 & 39.0 \\
$\begin{array}{l}\text { Text messaging is useful because it saves time over } \\
\text { telephone or face-to-face meetings }\end{array}$ & 52.2 & 15.5 \\
$\begin{array}{l}\text { Many clients respond more openly to workers through text } \\
\text { messaging }\end{array}$ & 46.3 & 9.6 \\
$\begin{array}{l}\text { Workers should generally give clients their cell phone } \\
\text { numbers }\end{array}$ & 24.2 & 29.5 \\
$\begin{array}{l}\text { Text messaging is generally a burden to workers because it } \\
\text { adds to their workload }\end{array}$ & 9.5 & 15.5 \\
$\begin{array}{l}\text { Text messaging is an effective means for workers to provide } \\
\text { services to clients }\end{array}$ & 42.0 & \\
\hline
\end{tabular}


Effectiveness of electronic communication. Respondents were asked to rate how effective they believe it is to use e-mail and text messaging for the following: communicate with co-workers in their agency about clients; provide factual information to clients; schedule, confirm, \& change appointments with clients; communicate with workers at another agency about clients; and provide ongoing services to clients. The ratings were based on a five point Likert-scale from (1) Very Ineffective to (5) Very Effective. As seen in Table 6, the majority of respondents $(92.7 \%)$ reported that they believe it is effective to communicate with co-workers in their agency about clients via e-mail. Many of the respondents (83.8\%) also reported that they believe that it is effective to communicate with workers at another agency about clients via email. Almost two-thirds of respondents reported that they believe that it is effective to provide factual information to clients via e-mail (71.4\%); and to schedule, confirm, and change appointments with clients via e-mail (71.3\%). Over half of the respondents $(53.7 \%)$ also reported that they believe it is effective to provide ongoing services to clients through the use of e-mail. In comparison, over half of the respondents $(64.7 \%)$ reported that they believe it is effective to schedule, confirm, and change appointments with clients via text messaging. Roughly one-third of respondents reported that they believe it is effective to use text messaging to communicate with co-workers in their agency about clients (29.4\%), provide ongoing services to clients (33.0\%), and provide factual information to clients (36.8\%). A smaller percentage of respondents (16.2\%) reported that they believe it is effective to communicate with workers at another agency about clients. 
Table 6. Respondent perceptions regarding the effectiveness of electronic communication use

\begin{tabular}{lcc} 
Tasks & $\begin{array}{c}\text { Email } \\
\text { Agree (4-5) }\end{array}$ & $\begin{array}{c}\text { Text Message } \\
\text { \% Agree (4-5) }\end{array}$ \\
\hline Communicate with co-workers in my agency about clients & 92.7 & 29.4 \\
Provide factual information to clients & 71.4 & 36.8 \\
Schedule, confirm, \& change appointments with clients & 71.3 & 64.7 \\
$\begin{array}{l}\text { Communicate with workers at another agency about } \\
\quad \text { clients }\end{array}$ & 83.8 & 16.2 \\
Provide ongoing services to clients & 53.7 & 33.0 \\
\hline
\end{tabular}

Difficulties related to electronic communication use. Respondents were asked to rate the frequency that they experienced the following difficulties while using electronic communication: I received an e-mail/text message not intended for me; I sent an e-mail/text message to the wrong person(s); my e-mail/text message led to a misunderstanding with other professionals; my email/text message led to a misunderstanding with a client; I received e-mail/text message that threatened, insulted, or harassed me; and a client's confidentiality was violated as a result of email/text messaging. (Note: E-mail use and text message use were measured independently, but were combined in this section for the purpose of clarity and consistency.) The ratings were based on five point Likert scale: (1) Never, (2) Rarely, (3) Sometimes, (4) Often, and (5) Daily. These findings, as seen in Table 7, show that over half of the respondents reported that they have experienced the following difficulties at some point: receiving an e-mail that was not intended for them (71.3\%), sending an e-mail to the wrong person(s) (63.2\%), and a misunderstanding with other professionals occurring as a result of an e-mail that was sent by the respondent (68.4\%). Nearly half of respondents (44.1\%) also reported that e-mail had led to a misunderstanding with a client at some point. More than one-fourth of respondents $(31.7 \%)$ reported that they had received an e-mail that threatened, insulted, or harassed them. A smaller percentage of respondents $(18.4 \%)$ reported that a client's confidentiality was violated at some point as a result of e-mail. In regard to text message use, a little over one-third of respondents 
$(36.0 \%)$ reported that they have received a text message that was not intended for them at some point. Nearly one-fifth of respondents $(19.1 \%)$ reported that they have, at some point, sent a text message to the wrong person(s). A similar percentage of respondents reported that they have sent a text message that led to a misunderstanding with other professionals (16.9\%) and that they have sent a text message that led to a misunderstanding with a client (16.9\%). A small percentage of respondents $(11.7 \%)$ reported having received a text message that threatened, insulted, or harassed them. An even smaller percentage of respondents $(8.1 \%)$ reported a violation of client confidentiality as a result of text message use.

Table 7. Difficulties experienced by respondents in a work-related situation while using electronic communication

\begin{tabular}{lcc} 
Difficulties & $\begin{array}{c}\text { Email } \\
\text { \% Occurred At } \\
\text { Some Point } \\
(2-5)\end{array}$ & $\begin{array}{c}\text { Text Message } \\
\text { \% Occurred At } \\
\text { Some Point } \\
(2-5)\end{array}$ \\
\hline I received a message not intended for me & 71.3 & 36.0 \\
I sent a message to the wrong person(s) & 63.2 & 19.1 \\
My use led to a misunderstanding with other professionals & 68.4 & 16.9 \\
My use led to a misunderstanding with a client & 44.1 & 16.9 \\
\hline I received a message threatened, insulted, or harassed me & 31.7 & 11.7 \\
A client's confidentiality was violated & 18.4 & 8.1 \\
\hline
\end{tabular}

\section{Qualitative Findings: Electronic Communication}

The survey for this study included two qualitative questions. The first qualitative question asked respondents to describe any ethical dilemmas that they have experienced while using text messaging, e-mail and/or social media either indirectly or directly with clients. In total, seventynine respondents answered this question. The second qualitative question asked respondents to describe any impact, other than the choices listed in the previous sections of the survey, that they have seen as a result of using these technologies with their clients. In total, seventy-seven respondents answered this survey question. Themes such as benefits of use, challenges of use 
and methods for avoiding presenting issues were identified throughout both questions. These questions were analyzed using thematic analysis. The quotations included in the qualitative analysis were edited for spelling and basic grammar mistakes before analysis. No editing was done that changed the meaning of the responses.

Benefits of Use. When asked to identify any ethical dilemmas that workers had experienced, many respondents also reported the benefits that they have seen as a result of using these technologies. Many respondents reported that young people prefer to use electronic communication. As one respondent stated, "There is no denying it, this is where we are headed. Young people today are going to be far easier to connect with via these means, as opposed to traditional methods of communication (i.e. snail mail)" Numerous respondents alluded to the increase of unlimited text messaging as a reason for increased text message communications. One respondent described this phenomenon in-depth:

“Many times my clients will have 'go-phones' and will run out of minutes, not being able to afford to buy more phone minutes or my clients will try to conserve their phone minutes by using the phone minimally. A lot of the 'go-phone' plans, however, allow unlimited text messaging. I have found that when I am unable to leave a voicemail or a line has been 'disconnected' I am often able to schedule appointments with that client via text, because although they are 'out of phone minutes' or not responding to phone calls they will respond to text messages because it doesn't cost them anything. Also, many of my clients attempt to avoid confrontation and will often more quickly respond to text messages."

Another respondent described a similar experience, as well as how this experience relates to email use: 
"I work with 18-21 year old clients who are aging out of foster care and typically on their own for the first time. Most don't have many minutes on their phone plans or are frequently changing numbers. I have found that since I have been allowed access to be able to text message on work phone, that client contact is far easier and more frequent. Email is the same result. Clients can easily get an email address for no cost and use that as one of their primary means of communication...."

Apart from the ease of comfort and increased response rates, some of the other benefits of electronic communication use that were reported by respondents included the following: convenience, increased effectiveness and efficiency, decreased no show rates, improved communications, easier documentation, easier scheduling, and greater connection between client and worker. As one respondent stated, "Email has made communication so much easier than years ago. This has essentially put an end to "phone tag", and has allowed one to be much more effective at work with respect to time, and saving time..." Another respondent reported, "I use text messages to remind clients of their appointments and it has decreased my 'no show' rate considerably....” In regard to documentation, respondents reported more effective documentation. For example, one respondent stated, "I continue to use emails because it is a highly effective form of communication especially since it provides that documentation."

Although some respondents reported that they do not actually use these technologies with clients, they did report their perceptions of use. For example, one respondent expressed:

"I do not have an agency cell phone. I only use my personal cell for business related matters but I do not share my cell number with clients. It would be very convenient to be able to use text messaging for brief communication with teens and to confirm or briefly communicate about appointment scheduling..." 
A few respondents reported that using these technologies have fostered a greater connection between client and worker. For example, one respondent stated:

"Text messaging is something most of my young clients in foster care use. It is a way for them to connect with me easier and makes me seem more accessible and on their level. I have several young clients that enjoy the use of text messaging to communicate. It is also a great tool for quickly confirming an appointment or meeting with a client."

Many respondents indirectly reported that they experience a variety of benefits as a result of using these electronic communication methods. The following respondent reported experiencing benefits such as easier scheduling, improved communications, faster response times and more efficient use of time:

"Regarding the above, I primarily use text messaging with clients and primarily related to scheduling appointments. I have found it to be very helpful as if the client is sleeping or working or busy with something else, they can see the message when it works for them. I appreciate getting text messages for the same reason. I haven't experienced any ethical dilemmas. My general thought about texting is that I think it has improved my communication with clients. Clients, particularly younger ones, get back to me with a response sooner than they would with a phone call. I was also able to scan and email a daycare provider list to a client and it was much more timely than sending the list in the mail.”

Another respondent reported benefits such as increased communication and responses, as well as greater comfort for clients. This respondent states:

"I have used my work cell phone to call and text my clients during work hours often. I believe that this has helped tremendously in communication and responses from my 
clients. In the past, when there were only office phone, it was often hard to get a hold of a worker as we are in and out of the office on client visits almost hourly. With the use of the work cell phone I am able to take calls when I'm out and about and answer simple questions for my clients. I have also noticed that some clients are more comfortable with responding by text message....”

Challenges of Use. The second theme discovered through thematic analysis was the idea that challenges have emerged as a result of using these technologies. Within this theme, three subthemes emerged. These sub-themes include harassment from clients, problems with privacy and confidentiality, and boundary concerns.

Harassment from clients. There were a few responses that were given that re-enforce the idea that these technologies have contributed to an increase of threats from clients. As one respondent reported, “....Unfortunately, one very ill client then had my cell phone number and during an extreme psychotic episode texted me accusations and threats. I was able to block her number and no other negative occurrences have happened.” Another respondent reported something similar, "I have had to stop client emails when they became volatile and ineffective. I told the client I will no longer to respond to any future emails and all correspondence must be in person or by telephone with me." A third respondent reported that an angry client had contacted her son through social media in the past. She stated, “.... a kid in foster care angry at me, found my son at school using social media and confronted him about me - said some nasty things to him about me....”

Privacy and confidentiality. Many respondents reported challenges related to privacy and confidentiality. For one respondent, the issues of privacy and confidentiality have dictated use of electronic communication altogether. As this respondent reported: 
"I avoid using these forms of electronic communication with clients due to the risk of violating confidentiality. The county where I work has advised that we should not use email with clients unless emails are encrypted, which is just a hassle to deal with. While I think there could be some instances where being able to send a quick email or text would be helpful, I avoid using these forms unless it is the only way to communicate with someone."

Other respondents alluded to the fact that these issues of privacy and confidentiality are also macro issues that not only exist within agencies, but also between agencies:

"With email, the issue is when sources outside of the county send private information via email attachments without the benefit of encryption (psych evals, school evals, IEP, treatment plans, etc.). When I have asked outside sources about encryption and assuring doc safety, they typically then agree to fax the doc instead of attach it to email. I think people innocently forget that hackers get information quickly and easily, and we need to be extra careful how personal information is shared between agencies, and other working professionals and school personnel...."

Boundary concerns. The most evident challenge that workers reported facing was how these technologies have contributed to greater boundary issues between the practitioners and clients. Numerous respondents reported how these communications have created blurred boundaries, where a worker may feel the need to be available 24/7. The following quotation illustrates the challenges with boundaries that electronic communication has created:

"If I am on vacation or out of the office for personal reasons and I receive a text message, the client expects an immediate response. I respond by saying I am not able to 
spend time to help them with their concern but provide information about who to contact in the office for immediate assistance."

Another respondent reported a similar issue:

"Occasionally with clients having my cell phone number they will text or call after hours and I don't respond if it's not between 8 and 4:30pm unless it's an emergency situation. Occasionally I've had to directly tell clients that their communication is not an emergency therefore they should contact me between 8 and 4:30pm Monday through Friday."

Many respondents also discussed how this challenge could become even more pressing if emergency or crisis situations arise for clients. One respondent reported how this has the potential to create an ethical dilemma if an emergency were to arise after hours:

"The use of personal cell phones for text messaging causes dilemmas to workers. There is no way to block the number. Clients are then able to text anytime of the day, night or weekends. If the worker reads the text, they are in a dilemma if it involves a crisis situation to have to respond during their off hours."

Another respondent described how not having a work cell phone further contributes to this issue: “Because I don't have a work cell phone, I give my clients my personal cell phone if it's difficult for them to reach me at my office during normal business hours. However, I have received text messages at $2 A M$ from clients and the content of the text is not an emergency or urgent matter. I don't respond to those texts until appropriate business hours unless it's an emergency."

One reported also addressed how these boundaries can get confused when clients use the same technologies to communicate with both social contacts and providers. This respondent stated: 
"I've had a few clients who try to engage in challenging arguments via text message, but they refuse to speak to me by phone or come to the office for an appointment. I won't have that type of conversation via text. I think the tone of boundaries can get confused when they can use the same medium of communication with providers the same as they would with social contacts.”

Other respondents reported similar scenarios that contribute to blurred boundaries, such as clients misunderstanding the context of the professional relationship. As one respondent stated, "Some clients tend to share way more than is necessary. Some clients may view it as a more "friendship" type relationship and then you need to re-establish boundaries more often with them."

Methods for Avoiding Challenges. The final theme that emerged in regard to electronic communication use was the idea that many respondents have either direct or indirect methods for avoiding problems that have emerged as a result of the use of electronic communication. These methods include actions such as following agency policy, only using electronic communication with certain clients, continuing to use face-to-face contact with clients, and limiting what is shared through electronic communication.

In regard to agency policy, one respondent stated, "Our agency generally does not text, e-mail, or use social media to work directly with clients...” Another respondent reported, "[There is a] potential for security breaches. County Policies are restrictive in our ability to use such means of communication." Some respondents reported that their agencies do not use these technologies specifically to avoid the aforementioned issues. As one respondent reported: 
“Our agency does not allow texting due to privacy issues, but because I give my cell number to clients, they will often text to me. Some people want to communicate via text and I am not able to honor that request in order to follow policy/honor their privacy."

Similarly, another respondent stated:

"I think sometimes clients want to be able to use email or text to communicate with me, but I tell them that the county discourages it as it could compromise their confidentiality...."

In regard to only using electronic communication with certain clients, one respondent reported, "I use it with very few clients. I only give my personal cell number to a select few. Clients can misuse the number so I am cautious about sharing it....” Another respondents stated, “...I have given two clients my personal cell phone number to use to coordinate meetings and after care. Both of the clients have been very respectful with my phone number and have used it properly...." A third respondent reported:

"I only give my cell number to clients whose only means of communication is texting.

This is usually due to not being able to afford minutes for their phones. $99 \%$ of those who I've given my number to have been teens that I have placed in foster care...."

One respondent stated that there is a "tendency to rely less on in-person contact," yet numerous respondents discussed the need for continued face-to-face contact. As one respondent stated, "These forms of communication should be used to enhance communication but should not be used to replace direct communication and contact with clients." The need for continued face-toface contact is also evidenced by the following respondent quotation:

"I use text message and email as many clients respond to this but not to a phone call. I prefer direct face-to-face communication as I often read body language and voice 
intonation when working with clients. As time goes on it seems that more of my clients prefer text and email and I am willing to do this but still require some face-to-face contact in order to feel that I am providing quality service to them."

Many clients also reported that they do not include any identifying information while using electronic communications. One respondent explained how not including identifying information was helpful in the past:

"I sent a message about a current case to a person other than the one intended, however the email did not include identifying information. I was thankful that the person who received the email would not be able to identify whom the information was about." Another respondent reported:

"My main concern about emails is confidentiality if there was some kind of security breach with my agencies email. Typically this has not been a problem because I do not share last names or identifying information in the emails that go outside this agency. I only email a client if they contact me via email or give me permission to email them. When emailing clients I keep messages short and with little information about their case.”

Some respondents reported how they prefer being overly cautious when it comes to sharing client information. This can be seen in the following statement:

"I use initials on all emails that go outside the agency, sometimes people have called, as they aren't sure whom I was referring to. I would rather have them call, as I will not use client names in emails." 
A few respondents also alluded to the need for encryption services if identifying information is shared through electronic communications. One example can be seen in the following respondent statement:

“....When I use email with colleagues regarding a client, our agency has an encryption service so I feel comfortable that confidentiality won't be broken (relatively comfortable). I have had direct emails with clients, but only do so if the client initiates an email with me, and then I only email benign information that would not impact confidentiality in any significant way.”

Numerous respondents reported the necessity of keeping the communications brief and only sharing minimal information. For many of respondents, and text messaging should only be used for things like brief check-ins, follow up, job leads, touching base, scheduling, receiving agency information, and questions about the law or licensing rules. As one respondent stated, “...I would not use any of them to discuss private matters."

\section{Quantitative Findings: Social Media}

Frequency of Use: Direct Social Media. The frequency of direct social media use with clients was examined in this study. Respondents were asked how frequently they use social media directly with clients. The response options were: never, rarely, sometimes, often, and daily (136). Before completing this section of the survey, respondents were informed that direct social media use with clients typically includes activities such as accepting friend and follower requests, personal messaging and liking posts. Clients were also directed to answer all survey questions in regard to direct social media use unless directed otherwise. The findings in Table 8 show that 118 respondents $(86.8 \%)$ reported that they never use social media directly with clients, 11 respondents $(8.1 \%)$ reported that they rarely use social media directly with clients, 6 
respondents (4.4\%) reported that they sometimes use social media directly with clients, and 1 respondent $(.7 \%)$ reported often using social media with clients. These findings show that a majority of respondents do not use social media directly with clients.

Frequency of Use: Indirect Social Media. The frequency of indirect social media use with clients was also examined in this study. Respondents were asked how frequently they use social media indirectly with clients. The response options were: never, rarely, sometimes, often, and daily (136). Before completing this section of the survey, clients were informed that indirect social media use with clients includes activities such as using social media for relationshipbuilding or social mapping with friends and family. The findings, as seen in Table 8 , show that 76 respondents $(55.9 \%)$ reported that they never use social media indirectly with clients, 34 respondents $(25.0 \%)$ reported that they rarely use social media indirectly with clients, 23 respondents $(16.9 \%)$ reported that they sometimes use social media indirectly with clients, and 3 respondents $(2.2 \%)$ reported that they often use social media indirectly with clients. These findings show that a majority of respondents never use social media indirectly with clients.

Table 8 . Frequency of direct and indirect social media use

\begin{tabular}{lccccc} 
Type of Technology & $\%$ Never & $\%$ Rarely & $\%$ Sometimes & $\%$ Often & $\%$ Daily \\
\hline Direct social media use & 86.8 & 8.1 & 4.4 & 0.7 & 0.0 \\
Indirect social media use & 55.9 & 25.0 & 16.9 & 2.2 & 0.0 \\
\hline
\end{tabular}

Impact of Social Media Use. The survey also measured how respondents perceive the impact of social media use on their work. The respondents were asked to mark which statement most accurately describes their experience with social media. The response options were: social media use has made my work with clients easier, there has been no change in my work with clients as a result of social media use, and social media use has made my work with clients harder (132). As seen in Table 9, the findings show that 18 respondents (13.2\%) reported that 
social media use has made their work with clients easier, 104 respondents $(76.5 \%)$ reported that there has been no change in their work with clients as a result of social media use, and 10 respondents $(7.4 \%)$ reported that social media use has made their work with clients harder. Four respondents $(2.9 \%)$ did not respond to this survey question. These findings show that a majority of respondents believe there has been no change in their work as a result of social media use.

Table 9. Respondent perceptions regarding the impact of social media use

Impact

Social media use has made my work with clients easier

There has been no change in my work with clients as a result of social media use

Social media use has made my work with clients harder
Social Media $(\%)$

13.2

76.5

7.4

Beliefs About Social Media Use. Respondents were asked to rate their agreement with the following statements: social media use with client information should not be used because it violates client confidentiality; many clients respond more openly to workers through social media; social media is an effective means for workers to provide services to clients; workers should generally accept friend/follower requests from clients on social media sites; workers should monitor clients' activities on social media websites; and workers should use social media indirectly with clients (i.e. relationship building, social mapping, etc.) (134). The ratings were based on a five point Likert-scale from (1) Strongly Disagree to (5) Strongly Agree. As seen in Table 10, over half of participants $(66.2 \%)$ reported that they agree that social media use with client information should not be used because it violates client confidentiality, whereas a small percentage of respondents $(9.5 \%)$ disagreed with this statement. Over half of respondents $(58.8 \%)$ reported that they neither agree nor disagree that many clients respond more openly to workers through social media. Only $10.3 \%$ of respondents agreed with this statement, compared to $28.7 \%$ of respondents who disagreed. Many respondents $(40.4 \%)$ disagreed that workers 
should monitor clients' activities on social media websites. Only one fifth of respondents $(22.8 \%)$ agreed that workers should monitor these activities. Roughly two-thirds of respondents $(35.3 \%)$ neither agreed nor disagreed that workers should monitor their clients' activities. Over half of the respondents $(59.5 \%)$ reported that they disagree with the statement that social media is an effective means for workers to provide services to clients, as compared to a small percentage $(5.1 \%)$ who agreed with this statement. Approximately one-third of respondents $(33.1 \%)$ neither agreed nor disagreed that social media is an effective means for providing services to clients. Over half of respondents (57.4\%) disagreed with the statement that workers should use social media indirectly with clients (i.e. relationship building, social mapping, etc.), whereas a small percentage of respondents $(8.8 \%)$ agreed with this statement. The largest percentage of respondents $(84.6 \%)$ disagreed that workers should generally accept friend/follower requests from clients on social media sites. Only one respondent (.7\%) agreed that workers should generally accept friend/follower requests from clients on social media sites.

Table 10. Respondent agreement with beliefs about social media use

\begin{tabular}{lcc}
\hline Beliefs & \% Agree (4-5) & \% Disagree (1-2) \\
\hline $\begin{array}{l}\text { Social media use with client information should not be used } \\
\text { because it violates client confidentiality }\end{array}$ & 66.2 & 9.5 \\
$\begin{array}{l}\text { Many clients respond more openly to workers through social } \\
\text { media }\end{array}$ & 10.3 & 28.7 \\
$\begin{array}{l}\text { Social media is an effective means for workers to provide } \\
\text { services to clients }\end{array}$ & 5.1 & 59.5 \\
$\begin{array}{l}\text { Workers should generally accept friend/follower requests } \\
\text { from clients on social media sites }\end{array}$ & 0.7 & 84.6 \\
$\begin{array}{l}\text { Workers should monitor clients' activities on social media } \\
\quad \text { websites }\end{array}$ & 22.8 & 40.4 \\
$\begin{array}{l}\text { Workers should use social media indirectly with clients (i.e. } \\
\text { relationship building, social mapping, etc.) }\end{array}$ & 8.8 & 57.4 \\
\hline
\end{tabular}

Effectiveness of social media use. Respondents were asked to rate how effective they believe it is to use social media for the following: communicate with co-workers in their agency 
about clients; provide factual information to clients; schedule, confirm, \& change appointments with clients; communicate with workers at another agency about clients; provide ongoing services to clients; and promote agency services and events (129). The ratings were based on a five point Likert-scale from (1) Very Ineffective to (5) Very Effective. The findings in Table 11 show that only two respondents $(1.5 \%)$ reported that they believe it is effective to communicate via social media with co-workers in their agencies. Similarly, only two respondents (1.5\%) believe it is effective to communicate via social media with workers at another agency about clients. Only two respondents $(1.4 \%)$ reported that they believe it is effective to use social media to schedule, confirm, and change appointments with clients. Similarly, two respondents (1.4\%) reported that they believe social media is an effective medium to provide ongoing services to clients. Seven respondents $(5.2 \%)$ reported that they believe it is effective to use social media for providing factual information to clients. In relation to promoting agency services and events, roughly one-fourth of respondents $(25.8 \%)$ reported that they believe that social media is an effective medium for doing so.

Table 11. Respondent perceptions regarding the effectiveness of social media use

\begin{tabular}{lc} 
Tasks & $\begin{array}{c}\text { Social Media } \\
\text { Agree (4-5) }\end{array}$ \\
\hline Communicate with co-workers in my agency about clients & 1.5 \\
Provide factual information to clients & 5.2 \\
Schedule, confirm, \& change appointments with clients & 1.4 \\
Communicate with workers at another agency about clients & 1.5 \\
Provide ongoing services to clients & 1.4 \\
Promote agency services and events & 25.8 \\
\hline
\end{tabular}

Difficulties related to social media use. Respondents were asked to rate the frequency that they experienced the following difficulties: a client attempted to add me as a friend on a social media website; a client saw something I posted on my personal social media page; I saw something that a client posted on his/her personal social media page; my personal social media 
use led to a misunderstanding with a client; I received a message from a client or client's family on a social media website that threatened, insulted, or harassed me; and a client's confidentiality was violated as a result of my personal social media use (134). The ratings were based on five point Likert scale: (1) Never, (2) Rarely, (3) Sometimes, (4) Often, and (5) Daily. Over half of respondents $(63.2 \%)$ reported that, at some point, they have seen something that a client posted on his/her personal social media page. In comparison, only one-fifth of respondents $(19.1 \%)$ reported that a client saw something that was posted on the respondent's personal social media page. These findings, as seen in Table 12, show that over half of the respondents $(54.3 \%)$ reported that a client has attempted to add them as a friend on a social media website. Only a small percentage of respondents reported that their personal social media use led to a misunderstanding with a client (3.7\%), that they received a message from a client's or client's family on a social media website that threatened, insulted, or harassed them $(2.2 \%)$; and that a client's confidentiality was violated as a result of their personal social media use (1.4\%).

Table 12. Difficulties experienced by respondents in a work-related situation while using social media

\begin{tabular}{lc}
\hline Difficulties & $\begin{array}{c}\text { Social Media } \\
\text { \% Occurred At } \\
\text { Some Point (2-5) }\end{array}$ \\
\hline $\begin{array}{l}\text { My personal social media use led to a misunderstanding with a client } \\
\text { I received a message from a client or client's family on a social media } \\
\text { website that threatened, insulted, or harassed me }\end{array}$ & 3.7 \\
$\begin{array}{l}\text { A client's confidentiality was violated as a result of my personal social } \\
\text { media use }\end{array}$ & 1.4 \\
A client attempted to add me as a friend on a social media website & 54.3 \\
A client saw something I posted on my personal social media page & 19.1 \\
\hline I saw something that a client posted on his/her personal social media page & 63.2 \\
\hline
\end{tabular}




\section{Qualitative Findings: Social Media}

As stated previously, the survey for this study included the two qualitative questions regarding ethical dilemmas that have been experienced by respondents related to text message, , and/or direct or indirect social media use; and any other impact, other than choices listed in previous sections of the survey, that respondents have seen as result of using these technologies with their clients. In relation to the first qualitative questions, themes for social media use were discovered using thematic analysis. These themes include boundary concerns, monitoring client activities, and methods for avoiding challenges. Again, the quotations included in the following qualitative analysis were edited for spelling and basic grammar mistakes, but no editing was done that would change the meaning of the responses.

Boundary Concerns. Many respondents reported experiencing situations that have affected the boundaries of the relationship between the worker and the client. In these situations, the boundaries between personal and professional appear to be blurred. As one respondent reports:

“With respect to social media, I personally stay away from that when dealing with clients and other professional staff. I severely limit who sees anything on my page, and share only with family and close friends no working relationships allowed!! Period. I think there is potential for individuals to blur the lines between personal and professional life.... and one needs to carefully consider this when they sign up for such media exchanges. I worry that there is difficulty with maintaining healthy boundaries if one allows the lines between personal and professional life to mix too much. NEVER should this happen with clients...EVER!!” 
Many of the respondents who reported boundary issues discussed how this has occurred as a result of receiving friend and follower requests from clients. One respondent stated, "I did receive a FB friend request from a client but I declined the request simply because I did not think the client should think I am their friend...." Another stated: "I do not use social media with clients because I think that can be misunderstood as a "friendship" to the client, therefore crossing safe and ethical boundaries." One respondent reported how he or she is currently managing the decision to accept friend request from clients:

"I do not want to be "friends" with my clients. I struggle with "ignoring" clients who friend me on Facebook. I typically "accept" initially and then "unfriend" so that they cannot see my page. Usually my clients have so many friends that they don't seem to notice....”

Similarly, another respondent reported how challenging it can be to deny friend requests: “....It is difficult to deny friend requests because you want your clients to feel connected to you, but I feel that to establish and keep appropriate boundaries, it is not appropriate to associate with clients outside of work."

A fourth respondent elaborated on these boundary issues, as well as what has been done to address these issues:

"Initially I allowed people to friend me on Facebook because I had no idea what it would mean. I had a client who got upset about seeing pictures of me with friends so I took clients off my personal page and started a business page which only has therapy related posts and that has gone well.”

One respondent described the parallel process between online and real-life interactions with clients and how this is related to the decision to deny friend requests on social media sites: 
“...I I draw a personal boundary at accepting friend requests on social media, but I do share personal information in person with my clients (stories about my own kids, funny things that happened to me, etc.) I do not accept friend requests because I want to keep my private life mostly private. And also I want to keep my client's private life private from my other social media friends...”

Along with boundary issues, one respondent reported how directly interacting with clients on social media sites could potentially become a confidentiality issue:

"I strongly believe that it is absurdly inappropriate to be friends/follow clients (former and present) on social media. It crosses boundaries and is not at all professional. It's a confidentiality issue as well because if a professional social worker becomes friends with and/or follows clients on social media, other people can see this and the identity of the worker's clients no longer remains confidential."

Other respondents expressed boundary issues that exist, unrelated to decision of whether or not to friend clients. For example, one respondent reported, "I am on a FB support group that a client is also on." Another respondent addressed how these boundary issues can become even more challenging in rural areas:

"Being in a rural area I have found on social media that some of my own friends are "friends" with clients or former clients. There hasn't been anything major that has happened as a result of this-but I find myself watching what I post on my friends site or what kind of comment I leave knowing that the client/former client could well see it. It is kind of annoying b/c I have my own personal life but feel like I still have to maintain my professional image if they may see my "informal" comments. Overall, though, it's not a huge deal." 
Monitoring Client Activities. Many respondents reported that they do use social media, particularly Facebook, to check on clients' activities. As one respondent stated, “....I do not "friend" clients on Facebook, although I will check their activities....” Another reported, “...I have also monitored social media sites as a way to gather information when a teenage client has run away or is involved in a dangerous behavior." Quite a few respondents reported that social media has been useful for finding information that is not otherwise reported by clients. For example, one respondent reported the following: "In Child Protection investigations, Facebook can be an effective way to find information about clients that they're not willing to share." One respondent reported that, although social media is not used within this worker's agency, this individual believes it would be an effective tool to monitor clients' activities:

"Our agency is not allowed open internet access so we do not have access to social media, but I believe it would be beneficial for our workers to be able to get on Facebook during work hours for the SOLE purpose of monitoring client activities. There are many times that fights, proof of substance use, and other helpful information is posted on Facebook that would be good to monitor a parent's sobriety, and who they are exposing their children to.”

Some respondents reported uncertainty about the ethics of searching for clients online. This can be seen in the following respondent quotation:

"Looking on a client's Facebook (or something similar) to see who they are hanging out with and if they are using and drugs or alcohol. Even though I have done this rarely, I feel it can be a violation of my client's privacy. However, it was also not protected information in the sense that they had it open for anyone to view. I still try not to use this 
if at all possible, but if it means my clients safety (drug and alcohol use; vulnerability with others they are with; etc.) then I feel there is some justification."

In contrast, some workers do not believe this is an ethical issue. One respondent reported: "As for social media, I do not accept friend requests from clients due to boundaries; however, I do at time attempt to look at their Facebook sites, sometimes to see if they are following their case plan requirements etc. I know that this is a current issue for some; however, I feel that if I am given permission and the site is not blocked there is no issue." Other respondents reported that checking in on clients online has the potential to impact the services offered by workers. As one respondent stated, "It is difficult to discuss concerns regarding issues that are discovered through social media if clients do not use their privacy settings." One respondent discussed a situation where a client's services were impacted as a result of the client's social media use:

"I referred a client to mental health urgent care services. A nurse at urgent care accessed the client's Facebook page \& reported to me that the posts were inconsistent with the psychotic symptoms the client reported to me. As a result, we were both less willing to take the client seriously \& were more convinced she was seeking drugs and/or financial benefits by faking symptoms.”

Another respondent reported that it can be difficult to decide what to do with the information that is found online:

"There have been times when clients put information out on Facebook for everyone to see that can conflict with activities that they are court ordered not to participate in. It is a struggle at times on what to do with this information, as they have not set their Facebook 
to private so they are authorizing information to be out there for 'everyone to see.' We often staff these dilemmas to see if info is appropriate to discuss with client or not."

A third respondent reported that discovering a former client's Facebook posts impacted how the worker perceived the former client:

"I was scrolling through Facebook and noticed posts from a client I visited. I think it gave me a slightly different view of her than I had when I visited her and feel if I were still seeing her (she graduated from our NFP program) this would have had some effect on my interactions with her."

One respondent also reported that checking in on clients creates issues within the relationship such as "eroding trust."

There were also a few respondents who stated that some workers have created fake social media identities in order to monitor clients. One individual responded to this question regarding ethical dilemmas by stating: "[sic] Using a false or made up Social Media Identity to find out information on a client.” Another respondent stated:

"I don't have direct clients, but I am aware of co-workers who search for clients on social media websites, even creating sham Facebook accounts so they can try to "friend" a client in order to find out more information. This strikes me as ethically questionable. I don't use any social media accounts myself, so I don't really know how it all works...."

Methods for Avoiding Challenges. Some respondents reported the need for avoiding social media use altogether. One respondent stated, “.... because social media can easily be accessed by others, it should not be used." Another stated, "I would never use social media to communicate with a client. My personal life is private and there is no reason to invite a client 
into my personal life." In contrast, some respondents discussed the benefits of using privacy settings in order to keep worker information private. As one respondent reported, “....I am very careful of what I put on Facebook because clients find ways to access. ” Similarly, another respondent stated:

"I avoid any social media interaction all together and inform clients of this. None of my clients have ever mentioned anything to me regarding my personal face book page, which is family only and private to the degree that anything on line is private."

Another respondent reported the need to keep these privacy settings enacted, as well as how searching for clients on social media sites relates to client privacy:

"It is against agency policy (and personal policy) to use social media to interact with participants. It is against HIPPA to search for participants too. I keep my own FB account locked so that people do not see my pictures, posts, and other information...."

Respondents also reported the need for discussing the professional relationship with the client, as well as how to re-establish boundaries after they have been effected by social media use. One respondent reported:

"I keep my personal social media account private, so my posts and pictures cannot be viewed by people who are not my friends. I have had friend requests or clients tell me they have seen my social media page, which lead to conversations regarding client/social worker relationships. “

Another respondent stated:

“...I don't ever connect with client attempts to connect with me on social media. Some clients have tried to connect with my family members or me and that is addressed with clients when they try." 
Another respondent addressed how these issues should be handled with former clients:

"I have used Facebook to search for clients in the past but have never added them as friends. If their page is public it is often easy to find information on there. I have had old clients message me and thank you for the work I did for them in their families to avoid ethical dilemmas I responded with a mailed letter stating I received their message however cannot be in contact via social media."

\section{Discussion}

\section{Purpose Statement and Research Questions}

The purpose of this research was to examine the impact that electronic communication and social media use have had on child welfare practice. The three research questions that emerged were:

1. Has the use of electronic communication and social media made working with youth easier for child welfare workers?

2. Has the use of electronic communication and social media introduced any difficulties for child welfare workers?

3. Have any challenges and/or benefits of electronic communication and social media use emerged that have not previously been discovered in the literature?

Impact of use. In regard to the first research question, it is clear that the use of e-mail and text messaging has made working with youth easier for child welfare workers. Nearly two-thirds of respondents reported that their work is easier as a result of e-mail use and over half of respondents reported that text messaging has had a similar impact on their work. Although respondents have stated that electronic communication has made their work easier, social media use does not appear to have had the same effect. This can be evidenced by the fact that three- 
fourths of respondents reported no change in their work with clients as a result of social media use. Interestingly, many respondents reported in the qualitative portion of the survey that they use social media to monitor client activities. It is likely that this activity would make working with youth either youth easier or harder. Based on reports that client services are impacted by what respondents have found on these websites and that these findings have sometimes negatively effected the professional relationship, it is likely that monitoring clients' online activities has made working with youth more difficult. Although many of the respondents reported that either they or their colleagues monitor clients' activities on social media websites, less than one-fourth of respondents reported that workers should monitor activities on social media websites. Interestingly, many respondents reported that they do not believe it is effective to use social media for the tasks that were measured in this study, which suggests that many respondents do not think that social media can be effectively utilized for work purposes. This finding, though, is inconsistent with respondent reports of checking in on clients via social media websites. Similarly, a majority of respondents reported that they had experienced a client attempting to add them as a friend on a social media website. Again, it is likely that this would also contribute to social media use making this work more difficult. Yet, as stated, a majority of workers do not think that social media use has had an impact on their work.

Difficulties related to use. The second research question attempted to examine if any difficulties have emerged for child welfare workers as a result of these technologies. The findings of this study support the idea that workers' believe that difficulties have emerged, albeit they occur fairly infrequently. These difficulties have occurred mostly for e-mail use, as opposed to text messaging and social media use, based on the fact that the greatest percentage of reported difficulties occurred for e-mail use. It is likely that there are more reported difficulties for e-mail 
use because this technology has been present in the realm of social work for longer than text messaging or social media use. Therefore, there has been more time for these difficulties to occur.

The qualitative portion of the survey was very telling in regard to the specific difficulties that practitioners have been experiencing. Before discussing these difficulties, it is important to note that there is an inconsistency in the findings regarding the reported impact of electronic communication and social media use. Although respondents reported in the quantitative portions of the survey that electronic communication has made their work with youth easier and social media has not had an impact on their work, many respondents reported difficulties as a result of these technologies in the qualitative portion of the survey. This inconsistency could be related to the fact that the qualitative content in the survey specifically seeks to explore difficulties, when in fact, the respondents do not perceive these difficulties to have such a great impact. On closer inspection of these difficulties, though, it is clear that electronic communication and social media use have introduced similar issues, in different forms. For example, both electronic communication and social media have introduced boundary difficulties for workers. For electronic communication, these boundary issues are related to the feeling of always needing to be available, as well as how this presents greater ethical issues when crises and emergencies arise. These issues also include how easy it is for the professional relationship to be misunderstood and misconstrued. For social media, these boundary issues are mostly related to the nature of the relationship between worker and client.

Issues with privacy and confidentiality were present for both electronic communication and social media. For e-mail and text message use, respondents reported that these issues exist mainly when they are used with other professionals. This is not surprising based on the fact that 
$92.7 \%$ of workers believe it is effective to use e-mail to communicate with co-workers and $83.8 \%$ believe it is effective to use e-mail to communicate with workers at another agency about clients. At the same time, over half of respondents reported that their e-mail use has led to a misunderstanding with other professionals at some point. Although there is a drop in how effective respondents believe it is to use text messaging for these activities, some of the respondents did report that misunderstandings with other professionals have occurred at some point. For social media, the issue of privacy and confidentiality has emerged for clients, as well as for workers. For clients, these issues exist due to workers' use of social media to monitor online activities of clients. Although there was no mention of whether or not these practitioners inform their clients of how they use social media to monitor activities, it appeared that they do not inform clients based on reports of how difficult it is to bring these findings back to the client after searching online. Many respondents also indirectly reported that monitoring client activities online has introduced difficulties for workers. This is evidenced by the fact that workers reported how this can erode trust, violate client privacy, impact the services that are offered to clients and impact the worker's view of the client.

Many of the respondents reported that they use a personal cell phone for work purpose, but within the qualitative portion of the survey, very few respondents reported that this has created difficulties. Similarly, many respondents reported working in rural areas, but only a couple of respondents had mentioned the difficulties that have emerged as a result of using electronic communication and social media while working in a rural area.

\section{Connections to the Current Literature}

In relation to the final research question, the findings of this study support the previous literature. The themes that emerged for electronic communication included benefits of use, 
challenges of use, and methods for avoiding these challenges. For social media, the themes that emerged from this study included boundary concerns, monitoring client activities, and methods for avoiding challenges. No themes emerged within the qualitative data that have not been discussed in some capacity in the previous literature; yet within these themes, there were elements that emerged that have not been directly addressed by the literature.

Electronic communication: benefits of use. Respondents' statements that many youth use "go phones" with unlimited text messaging as well as free e-mail services is consistent with previous findings by Reamer (2013), which stated that many young people prefer to use these technologies because they are less expensive than face-to-face services. Similar to the findings by Finn (2006), many of the respondents also reported that they have improved communications with their clients as a result of electronic communication use. More specifically, these reports support the idea that electronic communication has introduced more responsive interactions as compared to face-to-face communications. Respondents' statements also support that documentation and scheduling have improved as a result of electronic communication use (Bradley \& Hendricks, 2009; Bradley et al, 2011; Kassaw, 2002; Mishna et al., 2012; Reamer, 2011). Similar to findings by Bradley \& Hendricks (2009), respondents reported a greater feeling of comfort as a result of electronic communication use. The idea that electronic communication fosters a greater connection was also supported by the previous research (Tregeagle \& Darcy, 2007; Tregeagle, 2011; Whitaker, Torrico, Meruvia \& Jones, 2010). The only benefit that was found in the current research that had not been discussed in previous literature was the idea that the increase of electronic communication use has decreased no-show rates for clients. That said, much of the previous literature and the current findings have alluded to this. 
Electronic communication: challenges of use. The previous literature has stated that there is a possibility of ethical issues occurring when social workers use electronic communication (Kassaw, 2002; Mishna et al., 2012; Reamer, 2012; Reamer, 2013). The current findings support this statement. The greatest area of concern for the respondents in this study was professional boundaries, as evidenced by numerous reports mentioning the expectation that electronic communications allows workers to be available at any hour of the day. Contrary to the findings by Reamer (2013), which reported that this form of communication is helpful because it removes the barrier for clients who cannot access services during business hours, many respondents alluded to the fact that this feeling of constant availability was a challenge. This is similar to findings by Kassaw (2002), which addressed the challenges that this constant availability and accessibility creates for workers. This issue was reported by respondents to be even more pressing when clients experience after-hour emergencies. Previously, Mishna, et al. (2012) addressed how this "slippery slope" of electronic communication use has occurred for many workers due to overly friendly tones that occur while using these technologies (p.283). The current findings within this subtheme also support the previous findings by Mishna et al. (2012) regarding the formation of permeable boundaries that occur as a result of electronic communication use.

In terms of privacy and confidentiality, it has been reported within the previous literature that this challenge is a fairly common concern. Based on the current findings, it is clear that this issue has become even more concerning within the past few years. For example, in 2006, only $4.5 \%$ of respondents reported that a client's confidentiality was violated as a result of e-mail use (Finn, 2006). For the current respondents, this number has tripled in relation to e-mail use and doubled in relation to text message use. The fact that nearly three-fourths of current respondents 
have received an e-mail message not intended for them and one-third of respondents have sent an e-mail message to the wrong person is also important to mention at this point. Although it was not distinguished whether or not these messages contained private or confidential information, there is a greater chance that this has happened based on the high rates of sending messages to the wrong person and receiving messages intended for someone else

Interestingly, the challenge of harassment was not addressed in-depth in the previous literature. In 2006, only $10 \%$ of the respondents reported receiving a messaged via e-mail that threated, insulted, or harassed them (Finn, 2006). In contrast, roughly one-third of the current respondents reported receiving a threatening, insulting, or harassing e-mail at some point. There were also responses within the qualitative data that support the idea that workers are experiencing a greater amount of harassment from clients than they have in the past.

Electronic communication: methods for avoiding challenges. One of the ways that respondents reported that they avoid the challenges was to follow agency policy. This finding is in contrast to the findings from Finn (2006). At that point, there were no clear policies or procedures regarding e-mail communication. It appears that this has changed in the past eight years. Previous research has presented the idea that electronic communication has the potential to connect services to clients who have more difficulty accessing them (Ahmendani et al., 2011; Mishna et al., 2012; Reamer, 2013; Tregeagle, 2011). Many of the respondents in the current study also reported this belief. These respondents reported that they are selective about the clients they interact with through these technologies, but it can be assumed that these are clients who benefit from the use of electronic communication. It is also important to mention that the previous research supports the idea that electronic communication use should only supplement face-to-face services, as opposed to replacing them altogether, in order to avoid confusing the 
client and creating inappropriate boundaries (Kassaw, 2002; Reamer, 2011). Finn (2006)

presented the idea that e-mails may potentially violate confidentiality if it is sent to the wrong person. This likely explains why many respondents reported that they typically only send brief electronic communications that do not include identifying information. Respondents also mentioned the importance of encryption services, which has been suggested in the previous research (Finn, 2006; Kassaw, 2002).

Social media: boundaries. Similar to electronic communication use, boundary concerns were also reported in relation to social media use. These findings are consistent with research from Judd and Johnston (2012), where it was found that these blurred boundaries might potentially become an issue for social workers who use social media. Both the previous research and the current findings support the fact that workers find it difficult to manage these boundary issues. One of the greatest contributing factors to these blurred boundaries is the fact that many workers have had to manage friend and/or follower requests from clients on social media websites. Within this study, over half of the respondents reported that, at some point, a client had tried to add them as a friend on a social media website. One of the primary boundary issues that was reported by respondents was that accepting a friendship request on social media sites often contributes to clients misconstruing the professional relationship and believing it to be an actual friendship. Interestingly, as reported by Reamer (2012), when practitioners do not accept friend requests, though, clients may experience issues of rejection. This could be the reason why so many respondents reported that they feel poorly about denying friend requests from clients.

Social media: monitoring client activities. Perhaps the most interesting finding in the current study was the frequency by which workers reported that they monitor their clients' social media accounts. Almost three-fourths of respondents reported that they have seen something that 
a client posted on his/her personal social media page, yet only about one-fifth of respondents reported that they agree that workers should monitor clients' activities on social media websites. There is vey little research regarding practitioners' use of social media to monitor client activities online. Schneider and Evan (2011) have mentioned previously that smartphones have been helpful in doing so, but this phenomenon has not been examined in-depth. One respondent reported that they monitor the client to make sure the client is safe, but a majority of the respondents who mentioned that they monitor their clients appear to do so in order to find information on the client, rather than to assess their safety. This is similar to previous reports by Gabbard (2012). A handful of respondents mentioned that they feel justified in searching for clients online if client profiles are not private. In contrast, a few clients mentioned that they do not feel this is ethical and that violates the client privacy. As presented in the previous literature, it is not clear if it is appropriate to search for clients online or if conducting a search violates the professional relationship (Huremovic \& Rao, 2009). It was mentioned by a couple of respondents that finding this information by seeking it out on social media websites has the potential to erode trust in the relationship. This supports the previous findings that clients may feel less trusting of that their social worker's commitment to confidentiality and privacy guidelines (Gabbard et al., 2011; Judd \& Johnston, 2012). Unfortunately, this appears to be a continuous issue that has not yet been address in the literature.

In regard to monitoring client activities online, a new finding that emerged in this study is the phenomenon of child welfare practitioners creating fake social media accounts in order to become online "friends" with their clients. Two separate respondents mentioned this issue, which clearly presents a variety of issues that will need to be addressed in future research. It is important to mention that social workers are bound by the NASW Code of Ethics to provide 
services that are based on valid and informed consent (NASW, 2008). This means that searching for clients online without their knowledge, as well creating a false persona in order to monitor client activities, violates this social work ethic.

Social media: methods for avoiding challenges. Although previous literature has not addressed it, respondents in this study reported that avoiding social media use is one way to avoid these challenges. For practitioners who use social media, a few reported the need to discuss the nature of the professional relationship with clients in order to re-establish boundaries after issues emerge. The one finding within the current study that is supported by previous literature is the need for practitioners to use of all available privacy settings on social media sites in order to avoid problems (Gabbard et al., 2011; Gabbard, 2012). Numerous respondents reported this within the qualitative portion of the study.

\section{The Changes in Trends from 2006-2014}

The guiding force of the current research was based in Jerry Finn's study of e-mail use by direct service social workers in 2006. Interestingly, Finn's findings regarding e-mail use are now more comparable to the current findings regarding social media use. When comparing the responses from Finn's survey in 2006 and the current survey in 2014, the percentage of respondents who agreed with e-mail beliefs in 2006 is very similar to the percentage of respondents who agreed with the same beliefs regarding social media in the current study. For example, in 2006, over half or respondents $(58.1 \%)$ reported that e-mail with client information should not be used because it violates confidentiality. The current findings show that only onefifth of respondents feel this same way about e-mail use, yet over half of the respondents $(66.2 \%)$ reported that they now feel this way about social media use. The same is true for many of the findings regarding difficulties experienced by respondents in work-related situations. The 
percentages related to difficulties experienced via e-mail in 2006 now more closely resemble the percentages related to difficulties experienced via social media in 2014 . Table 13 and Table 14 have been included in order to show the comparison of responses from the surveys administered in 2006 and 2014. Although there is no way to tell where future trends will go, it is interesting to note that perhaps in another eight years, social media use will become as universally accepted within social work practice as e-mail use is today.

Table 13. Comparison of respondent agreement with beliefs regarding e-mail, text message, and social media from 2006-2014

\begin{tabular}{|c|c|c|c|c|}
\hline Beliefs & $\begin{array}{l}\text { E-mail } \\
\text { (2006) } \\
\% \text { Agree } \\
(4-5) \\
\end{array}$ & $\begin{array}{l}\text { E-mail } \\
\text { (2014) } \\
\% \text { Agree } \\
(4-5) \\
\end{array}$ & $\begin{array}{c}\text { Text } \\
\text { Message } \\
\text { (2014) } \\
\% \text { Agree } \\
(4-5) \\
\end{array}$ & $\begin{array}{c}\text { Social } \\
\text { Media } \\
\text { (2014) } \\
\% \text { Agree } \\
(4-5) \\
\end{array}$ \\
\hline $\begin{array}{l}\text { E-mail/Text messaging/Social media use } \\
\text { with client information should not be used } \\
\text { because it violates client confidentiality }\end{array}$ & 58.1 & 18.4 & 27.2 & 66.2 \\
\hline $\begin{array}{l}\text { Many clients respond more openly to } \\
\text { workers through e-mail/text } \\
\text { messaging/social media }\end{array}$ & 13.8 & 36.0 & 46.3 & 10.3 \\
\hline $\begin{array}{l}\text { E-mail/Text messaging/Social media is an } \\
\text { effective means for workers to provide } \\
\text { (therapeutic) services to clients }\end{array}$ & 12.3 & 55.9 & 42.0 & 5.1 \\
\hline $\begin{array}{l}\text { E-mail/Text messaging is useful because it } \\
\text { saves time over telephone or face-to-face } \\
\text { meetings }\end{array}$ & 60.0 & 72.1 & 52.2 & -- \\
\hline $\begin{array}{l}\text { Social workers should generally give clients } \\
\text { their work e-mail address/cell phone } \\
\text { number }\end{array}$ & 24.2 & 66.9 & 24.2 & -- \\
\hline $\begin{array}{l}\text { E-mail/Text messaging is generally a } \\
\text { burden to social workers because it adds to } \\
\text { the workload }\end{array}$ & 13.0 & 5.9 & 9.5 & -- \\
\hline $\begin{array}{l}\text { Workers should generally accept } \\
\text { friend/follower requests from clients on } \\
\text { social media sites }\end{array}$ & -- & -- & & 0.7 \\
\hline $\begin{array}{l}\text { Workers should monitor clients' activities } \\
\text { on social media websites }\end{array}$ & -- & -- & & 22.8 \\
\hline $\begin{array}{l}\text { Workers should use social media indirectly } \\
\text { with clients (i.e. relationship building, social } \\
\text { mapping, etc.) }\end{array}$ & -- & -- & & 8.8 \\
\hline
\end{tabular}


Table 14. Comparison of difficulties experienced by respondents in a work-related situation while using e-mail, text message, and social media from 2006-2014

\begin{tabular}{|c|c|c|c|c|}
\hline Difficulties & $\begin{array}{c}\text { E-mail } \\
(2006) \\
\% \text { Occurred } \\
\text { At Some } \\
\text { Point } \\
(2-5)\end{array}$ & $\begin{array}{c}\text { E-mail } \\
(2014) \\
\% \text { Occurred } \\
\text { At Some } \\
\text { Point } \\
(2-5) \\
\end{array}$ & $\begin{array}{c}\text { Text } \\
\text { Message } \\
(2014) \\
\% \text { Occurred } \\
\text { At Some } \\
\text { Point } \\
(2-5)\end{array}$ & $\begin{array}{c}\text { Social } \\
\text { Media } \\
(2014) \\
\% \text { Occurred } \\
\text { At Some } \\
\text { Point } \\
(2-5) \\
\end{array}$ \\
\hline $\begin{array}{l}\text { I received a message not } \\
\text { intended for me }\end{array}$ & 50.0 & 71.3 & 36.0 & --- \\
\hline $\begin{array}{l}\text { I sent a message to the wrong } \\
\operatorname{person}(\mathrm{s})\end{array}$ & 31.9 & 63.2 & 19.1 & --- \\
\hline $\begin{array}{l}\text { My use led to a } \\
\text { misunderstanding with other } \\
\text { professionals }\end{array}$ & 26.6 & 68.4 & 16.9 & --- \\
\hline $\begin{array}{l}\text { My use led to a } \\
\text { misunderstanding with a client }\end{array}$ & 6.2 & 44.1 & 16.9 & 3.7 \\
\hline $\begin{array}{l}\text { I received a message threatened, } \\
\text { insulted, or harassed me }\end{array}$ & 10.0 & 31.7 & 11.7 & 2.2 \\
\hline $\begin{array}{l}\text { A client's confidentiality was } \\
\text { violated }\end{array}$ & 4.5 & 18.4 & 8.1 & 1.4 \\
\hline $\begin{array}{l}\text { A client attempted to add me as } \\
\text { a friend on a social media } \\
\text { website }\end{array}$ & -- & --- & --- & 54.3 \\
\hline $\begin{array}{l}\text { A client saw something I posted } \\
\text { on my personal social media } \\
\text { page }\end{array}$ & -- & --- & --- & 19.1 \\
\hline $\begin{array}{l}\text { I saw something that a client } \\
\text { posted on his/her personal } \\
\text { social media page }\end{array}$ & -- & --- & --- & 63.2 \\
\hline
\end{tabular}

\section{Limitations of the Current Study}

There are clear limitations to the current study. As stated previously, this study was only exploratory. Because of this, many of the findings were purely descriptive; no inferential statistics were used to analyze the data. This means that the findings cannot truly be generalized to all child welfare workers. Another limitation lies in the fact that the survey was conducted online. It has been acknowledged within the methodology that this had the potential to create a bias of respondents who were more knowledgeable regarding these technologies. Another 
limitation of this online survey, though, was that there was no way to illicit more elaborate responses within the qualitative framework. If the qualitative portion had been completed through in-person interviews, these questions could have been explained in greater depth.

\section{Implications for Social Work Practice}

Since the emergence of electronic technologies into the field of social work in the 1980's, the profession has struggled to stay current with ethical and professionalism standards related to the use of these technologies. Social workers within the profession have also struggled with balancing the benefits and challenges that these technologies have created. Not only do concerns regarding technology use still exist roughly three decades later, but these concerns continue to evolve with new and emerging technologies. This exploratory study offered insights into what the impact of these technologies has been up until this point. Based on these findings, coupled with previous research, it appears that electronic communication and social media are here to stay. Although the findings indicated some methods that current practitioners are using to avoid any potential challenges of these technologies, it will be imperative that social work professionals continue to search for ways to effectively manage the challenges that emerge. It will also be important for social work professionals to receive up-to-date education and training regarding the ethical application of these technologies into their practice.

\section{Implications for Future Research}

Overall, there is a greater amount of disparity that exists within the field regarding the ethical use of social media, as opposed to electronic communication. At this point, it appears as though there is more consistency within the literature regarding electronic communications. Ultimately, though, the findings of this study give an example of current trends for electronic communication and social media use in child welfare practice. These findings can be used as a 
starting point for future research regarding the intersection of technology (specifically, social media) and social work practice. For example, one of the findings of this study was that many respondents who work within the child welfare system are currently using social media to track their clients. In the future, it would likely prove beneficial to continue to explore this; perhaps by examining further how monitoring client activities online impacts the client-worker relationship.

Many respondents in this study had different beliefs and opinions regarding the ethical use of these technologies. It is likely that respondents have not had the opportunity to explore and identify the role that social media has in their own practice. It is also likely that the trends of social media use will continue to change as time passes and as new technologies begin to emerge. As this occurs, it will be imperative for future research to examine the effect that social media continues to have on social work practice. This will also be helpful for decreasing feelings of ambiguity and uncertainty for workers who suddenly find themselves immersed in new technologies that are impacting their work. Future research will need to stay current with emerging technologies and the impact that these have on social work practice.

\section{Conclusion}

The purpose of this research was to examine the intersection of technology and child welfare practice. More specifically, the impact that electronic communication and social media have had on child welfare practice was explored in-depth. The findings of this exploratory study affirmed and expanded on findings in the previous literature. As new technologies have emerged, child welfare workers have begun to experience distinct benefits and challenges related to the use of these technologies directly or indirectly with their clients. The benefits discovered in this study included convenience, increased effectiveness and efficiency, decreased no show rates, improved communications, easier documentation, easier scheduling, and greater connection 
between client and worker. Some of the challenges included boundary concerns, issues with privacy and confidentiality, threatening or harassing communications, and ethical issues related to monitoring online activities of clients. Methods for avoiding these challenges, such as following agency policy and re-establishing boundaries with clients, were also discussed. As social work practice and technology continue to become more integrated, there is a need for more research on the impact of these technologies, as well as how social workers can ethically and effectively manage emerging challenges. 


\section{References}

Ahmendani, B. K., Harold, R. D., Fitton, V. A., \& Shifflet Gibson, E. D. (2011, October). What adolescents can tell us: Technology and the future of social work education. Social Work Education, 30(7), 830-846. doi:10.1080/02615479.2010.504767

Bodner, C., \& Knapp, D. (2011). Finding family on Facebook. University of Minnesota Center for Advanced Studies in Child Welfare: CW 360, 28.

Boyd, D. (2007). Why youth (heart) social network sites: The role of networked publics in teenage social life. The John D. and Catherine T. MacArthur Foundation Series on Digital Media and Learning, 119- 142.

Bradley, L. J., \& Hendricks, B. (2009, July). E-mail and Ethical Issues. The Family Journal: Counseling and Therapy for Couples and Families, 17(3), 267-271. doi:10.1177/1066480709338293

Bradley, L. J., Hendricks, B., Lock, R., Whiting, P., \& Parr, G. (2011, January). E-mail Communication: Issues for Mental Health Counselors. Journal of Mental Health Counseling, 33(1), 67-79. Retrieved September 10, 2012

Bronfenbrenner, U. (1994). Ecological models of human development. In International Encyclopedia of Education, Vol. 3, $2^{\text {nd }}$. Ed. Oxford: Elsevier.

Dawson, B.G., Klass, M.D., Guy, R.F., \& Edgley, C.K. (1991). Understanding social work research. Boston, MA: Allyn \& Bacon. Dudley, J.R. ( 2003).

Finn, J. (2006). An Exploratory Study of E-mail use by Direct service Social Workers. Journal of Technology in Human Services, 24(4), 1-20. doi:10.1300/J017v24n04_01

Finn, J. (2011). Supporting foster families with internet and communications technology. University of Minnesota Center for Advanced Studies in Child Welfare: CW 360, 17. 
Finn, J. \& B. Kerman, B. (2003). Internet risks for foster families online. Journal of Technology in Human Services, 22 (4), 21-38.

Fursland, E. (2011). Social networking and adoption. University of Minnesota Center for Advanced Studies in Child Welfare: CW 360, 20.

Gabbard, G. O. (2012, May). Clinical Challenges in the Internet Era. American Journal of Psychiatry, 169(5), 460-463. Retrieved September 10, 2012

Gabbard, G. O., Kassaw, K. A., \& Perez-Garcia, G. (2011, May). Professional Boundaries in the Era of the Internet. Journal of Academic Psychiatry, 35(3), 168-174. Retrieved September 10, 2012

Huremovic D. \& Rao N.R (2009). Beyond doctor-patient relationship in cyberspace: Pitfalls, transgressions, and guidelines (when therapists and patients Google each other). In 2009 Annual Meeting Syllabus and Scientific Proceedings. Washington, DC, American Psychiatric Association, 212-213

Judd, R. G., \& Johnson, L. B. (2012). Ethical Consequences of Using Social Network Sites for Students in Professional Social Work Programs. Journal of Social Work Values and Ethics, 9(1), 5-10. Retrieved September 10, 2012

Kassaw, K. (2002). The Ethics of E-mail Communication in Psychiatry. The Psychiatric clinics of North America, 25(3), 665-674. Retrieved September 21, 2012

LaMendola, W. Glastonbury, B, \& Toole, $\square$ S. (Eds.). (1989). A casebook of computer applications in the social and human services. Binghamton, NY: Haworth Press Ledesma, K., \& Vasavant, V. (2011). Enhancing the reach and outcomes of child welfare programs through social media. University of Minnesota Center for Advanced Studies in Child Welfare: CW 360, 10. 
LeMendola, W. (2011). Child welfare in technology. University of Minnesota Center for Advanced Studies in Child Welfare: CW 360, 4-12.

Lenhart, A., Ling, R., Campbell, S., \& Prucell, K. (2010, April 20). Teens and mobile phones [Electronic version]. Pew Research Center, 1-114.

Livingstone, S. (2011). Social networking: Risks and opportunities for youth. University of Minnesota Center for Advanced Studies in Child Welfare: CW 360, 23.

Madden, M., Lenhart, A., Duggan, M., Cortesi, S., \& Gasser, U. (2013, March 13). Teens and Technology 2013. Pew Research Center, 1-19. Retrieved from http://www.pewinternet.org/Reports/2013/Teens-and-Tech.aspx

Miller, R. (2011). Using social media in child welfare. University of Minnesota Center for Advanced Studies in Child Welfare: CW 360, 35.

Mishna, F., Bogo, M., Root, J., Sawyer, J., \& Khoury-Kassabri, M. (2012, September). "It just crept in": The Digital Age and Implications for Social Work Practice. Clinical Social Work Journal, 40(3), 277-286. doi:10.1007/s10615-012-0383-4

Monette, D.R., Sullivan, T. J. \& DeJong, C.R. (2011). Applied social research: A tool for the human services (8th Ed.). Belmont, CA: Brooks/Cole

National Association of Social Workers. (2008). Code of Ethics of the National Association of Social Workers. Retrieved September 10, 2012 from http://www.naswdc.org/pubs/code/code.asp

National Association of Social Workers \& Association of $\square$ Social Work Boards. (2005). NASW and ASWB standards for technology and social work practice. Washington, DC: Authors.

Reamer, F.G. (2009, November). Eye on ethics: Novel boundary challenges—social networking. 
Social Work Today. Retrieved December 19, 2012 from

http://www.socialworktoday.com/news/eoe_111309.shtml

Reamer, F.G. (2011, July). Eye on ethics: Developing a social media ethics policy. Social Work

Today. Retrieved November 10, 2012 from

http://www.socialworktoday.com/news/eoe_070111.shtml

Reamer, F.G. (2012, November). Practicing social work in an electronic world: Ethical and risk-management issues. Workshop presented for NASW MN Chapter, St. Paul, MN.

Reamer, F. G. (2013, April). Social work in a digital age: Ethical and risk management challenges. Social Work, 58(2), 163-172. doi:10.1093/sw/swtOO3

Rideout, V.J., Foehr, U.G., \& Roberts, D.F. (2010, January). Generation m: Media in the lives of 8- to 18-year-olds [Electronic version]. The Henry J. Kaiser Family Foundation, 1-79.

Robb, M. (2011, January). Pause Before Posting: Using Social Media Responsibly. Social Work Today, 8-11. Retrieved September 17, 2012

Schneider, S., \& Evans, M. (2011). Mobile technologies and child welfare. University of Minnesota Center for Advanced Studies in Child Welfare: CW 360, 16.

Schopler, J. H., Abell, M. D., \& Galinsky, M. J. (1998, May). Technology-based groups: A review and conceptual framework for practice [Electronic version]. Social Work, 43(3), 254-259.

Tregeagle, S., \& Darcy, M. (2007, July 26). Child welfare and information and communication technology: Today's challenge. British Journal of Social Work, 38, 1481-1498. doi:doi:10.1093/bjsw/bcm048 
Tregeagle, S. (2011). A challenge to child welfare professionals: Using new communication technologies with young people and their families. University of Minnesota Center for Advanced Studies in Child Welfare: CW 360, 24.

Weber State University. (n.d.). The ecological perspective of development. In CHF 1500:

Human Development. Retrieved November 18, 2013, from

http://faculty.weber.edu/tlday/human.development/ecological.htm

Whitaker, T., Torrico Meruvia, R. \& Jones, A. (2010). Child Welfare Social Workers' Attitudes Toward Mobile Technology Tools: Is There a Generation Gap? Washington, DC. NASW. 


\section{APPENDIX A \\ Consent Form \\ University of St. Thomas \\ Clinical Research Project: \\ Child Welfare Workers' Attitudes Regarding the Impact of $\square$ Electronic Communication and Social Media Use with Clients IRB Number \#545649-1}

I am conducting a study about child welfare workers' attitudes regarding the impact of electronic communication and social media use with clients. The purpose of this study is to explore how child welfare workers perceive the impact of using e-mail, text messaging and social media use with their clients. I invite you to participate in this research. You were selected as a possible participant because you are a professional who works or has worked with youth and families. Please read the following before agreeing to be in the study.

This study is being conducted by: Sarah Breyette, MSW student at the University of St. Thomas - St. Catherine University School of Social Work under the guidance of Katharine Hill, PhD., MPP, LISW, MSW and Professor in the School of Social Work at the University of St. Thomas St. Catherine University.

\section{Background Information:}

The purpose of this study is to explore child welfare workers' attitudes regarding the impact of electronic communication and social media use with clients.

\section{Procedures:}

If you agree to be in this study, you will be asked to complete an online questionnaire that will take approximately twenty minutes to complete.

\section{Risks and Benefits:}

The study has minimal risk. The questionnaire data will only be used for the purpose of this study and will be immediately destroyed upon completion. You will only be answering questions related to your perceptions and do not have to answer any questions that make you feel uncomfortable. There are no direct benefits to participating in this study.

\section{Confidentiality:}

The records of this study will be kept confidential. The survey will be anonymous. No identifiable information will be collected. Due to this fact, no identifiable information will be used in the data analysis or final report of the findings. The records that will be created include questionnaire data that will be stored in a password-protected document on the principle investigator's password-protected personal computer. This computer will not be accessed by anyone other than the principle investigator. All data will be destroyed upon completion of the study, no later than June 1, 2014. 


\section{Voluntary Nature of the Study:}

Your participation in this study is entirely voluntary. Your decision whether or not to participate will not affect your current or future relations with the University of St. Thomas or St. Catherine University. If you decide to participate, you are free to withdraw at any time. Should you decide to withdraw, the data already collected will only be used with your permission. You are also free to skip any questions that you do not want to answer.

\section{Contacts and Questions:}

My name is Sarah Breyette. If you have questions, you may contact me at 712-240-9192 or email me at brey6924@stthomas.edu. You may also contact my professor and advisor for this study, Katharine Hill, at 651-962-5809 or katharine.hill@stthomas.edu. You may also contact the University of St. Thomas Institutional Review Board at 651-962-5341 with any questions or concerns.

Completion of the survey implies your consent. $\square$ If you agree to participate in this study, please click the next button to be directed to the survey. 


\section{APPENDIX B \\ Electronic Communication and Social Media Survey}

\section{DEMOGRAPHICS}

1. What is your age?

2. What state do you live in?

3. At what kind of agency do you work?

Public

Private

Tribal

School

Clinical

Other:

4. Characteristics of the place where you work?

Rural

Suburban

Urban

Mixed

5. How long have you been in your field of work?

$0-5$ years

6-10 years

11-15 years

16-20 years

$20+$ years

\section{E-MAIL USE}

Please rank the following: (Never, Rarely, Sometimes, Often, Daily)

How frequently do you use e-mail with clients?

Please mark which statement most accurately describes your experience with e-mail use:

E-mail use has made my work with clients easier

There has been no change in my work with clients as a result of e-mail use

E-mail use has made my work with clients harder

How effective do you believe it is for workers to use e-mail for the following: (Very Ineffective, Ineffective, Neither Effective nor Ineffective, Effective, Very Effective)

Communicate with co-workers in my agency about clients

Provide factual information to clients

Schedule, confirm, \& change appointments with clients

Communicate with workers at another agency about clients

Provide ongoing services to clients 
Please indicate your level of agreement with the following statements about e-mail: (Strongly

Disagree, Disagree, Neither Agree nor Disagree, Agree, Strongly Agree)

E-mail with client information should not be used because it violates client

confidentiality

E-mail is useful because it saves time over telephone or face-to-face meetings

Many clients respond more openly to workers through e-mail

Workers should generally give clients their e-mail address

E-mail is generally a burden to workers because it adds to their workload

E-mail is an effective means for workers to provide ongoing services to clients

How often has e-mail created any of the following difficulties for you in a work-related situation:

(Never, Rarely, Sometimes, Often, Daily)

I received an e-mail not intended for me

I sent an e-mail to the wrong person(s)

My e-mail led to a misunderstanding with other professionals

My e-mail led to a misunderstanding with a client

I received e-mail that threatened, insulted, or harassed me

A client's confidentiality was violated as a result of e-mail

\section{TEXT MESSAGE USE}

For work purposes, which of the following do you use?

Work cell phone

Personal cell phone

No cell phone

*If "No Cell Phone" is selected, survey will skip to the next section on social media use

Please rank the following: (Never, Rarely, Sometimes, Often, Daily)

How frequently do you use text messaging with clients?

Please mark which statement most accurately describes your experience with text messaging:

Text message use has made my work with clients easier

There has been no change in my work with clients as a result of text message use

Text message use has made my work with clients harder

How effective do you believe it is for workers to use text messaging for the following: (Very

Ineffective, Ineffective, Neither Effective nor Ineffective, Effective, Very Effective)

Communicate with co-workers in my agency about clients

Provide factual information to clients

Schedule, confirm, \& change appointments with clients

Communicate with workers at another agency about clients

Provide ongoing services to clients

Please indicate your level of agreement with the following statements about text messaging: (Strongly Disagree, Disagree, Neither Agree nor Disagree, Agree, Strongly Agree)

Text messaging with client information should not be used because it violates client confidentiality 
Text messaging is useful because it saves time over telephone or face-to-face meetings

Many clients respond more openly to workers through text messages

Workers should generally give clients their cell phone numbers

Text messaging is generally a burden to workers because it adds to their workload Text messaging is an effective means for workers to provide services to clients

How often has text messaging created any of the following difficulties for you in a work-related situation: (Never, Rarely, Sometimes, Often, Daily)

I received a text message not intended for me

I sent a text message to the wrong person(s)

My text message led to a misunderstanding with other professionals

My text message led to a misunderstanding with a client

I received a text message that threatened, insulted, or harassed me

A client's confidentiality was violated as a result of a text message

\section{SOCIAL MEDIA USE}

Note: Social media sites are websites where the primary function is social networking. These websites allow users to connect with others online. Many social media websites allow users to share updates and photographs as well as content found online. Google+, LinkedIn, Facebook, Twitter and Instagram are all examples of social media websites. Direct social media use with clients typically includes activities such as accepting friend and follower requests, personal messaging and liking posts. Indirect social media use with clients includes activities such as using social media for relationship-building or social mapping with friends and family. Unless otherwise indicated, please answer the following questions in regard to direct social media use with clients.

Please rank the following: (Never, Rarely, Sometimes, Often, Daily)

How frequently do you use social media directly with clients?

How frequently do you use social media indirectly with clients?

Please mark which statement most accurately describes your experience with social media:

Social media use has made my work with clients easier

There has been no change in my work with clients as a result of social media use

Social media use has made my work with clients harder

How effective do you believe it is for workers to use social media for the following: (Very

Ineffective, Ineffective, Neither Effective nor Ineffective, Effective, Very Effective)

Communicate with co-workers in my agency about clients

Provide factual information to clients

Schedule, confirm, \& change appointments with clients

Communicate with workers at another agency about clients

Provide ongoing services to clients

Promote agency services and events 
Please indicate your level of agreement with the following statements about social media: (Strongly Disagree, Disagree, Neither Agree nor Disagree, Agree, Strongly Agree)

Social media use with client information should not be used because it violates client confidentiality Many clients respond more openly to workers through social media Social media is an effective means for workers to provide services to clients Workers should generally accept friend/follower requests from clients on social media sites

Workers should monitor clients' activities on social media websites Workers should use social media indirectly with clients (i.e. relationship building, social mapping, etc.)

How often has social media created any of the following difficulties for you in a work-related situation: (Never, Rarely, Sometimes, Often, Daily)

A client attempted to add me as a friend on a social media website A client saw something I posted on my personal social media page I saw something that a client posted on his/her personal social media page My personal social media use led to a misunderstanding with a client I received a message from a client or client's family on a social media website that threatened, insulted, or harassed me A client's confidentiality was violated as a result of my personal social media use

Please describe any ethical dilemmas that you have experienced while using text messaging, $e$ mail, and/or social media either indirectly or directly with clients:

Other than the choices in the previous sections, please describe any other impact you have seen as a result of using text messaging, e-mail, and/or social media either indirectly or directly with clients:

Please note: Multiple items throughout this survey were adapted from a similar study which examined the use of e-mail by direct service social workers. For further reading, the reference can be found here:

Finn, J. (2006). An Exploratory Study of E-mail Use by Direct Service Social Workers. Journal of Technology in Human Services, 24(4), 1-20. doi:10.1300/J017v24n04_01 